Universidad de Talca - Facultad de Ciencias Jurídicas y Sociales

El ámbito funcional de las comisiones paritarias en el ordenamiento jurídico español.

Un antecedente normativo comparado de las comisiones bipartitas

Rodrigo Palomo Vélez - Diego Villavicencio Pinto

Trabajo recibido el 13 de enero de 2019 y aprobado el 9 de abril de 2019

\title{
El ámbito funcional de las comisiones paritarias en el ordenamiento jurídico español. Un antecedente normativo comparado de las comisiones bipartitas para la implementación y seguimiento del cumplimiento de instrumentos colectivos en Chile*
}

\author{
The functional scope of the paritary commissions in the Spanish leGal \\ ORDER. A COMPARATIVE LEGAL ANTECEDENT OF THE BIPARTITE COMMISSIONS \\ FOR THE IMPLEMENTATION AND MONITORING OF THE COMPLIANCE OF \\ COLLECTIVE INSTRUMENTS IN CHILE
}

\author{
Rodrigo Palomo Vélez* \\ Diego VILLAVICENCIO PINTO"*
}

\begin{abstract}
RESUMEN
Este artículo analiza el ámbito funcional de las comisiones paritarias de la negociación colectiva en el ordenamiento jurídico español, centrando el estudio en las competencias más relevantes de dichas comisiones (con especial énfasis en la delimitación entre la administración y la negociación del convenio colectivo, y el papel de estas comisiones en la solución extrajudicial de conflictos laborales), y en la eficacia jurídica de sus pronunciamientos en el ejercicio de sus distintas funciones.

El estudio del modelo español importa una contribución al actual debate sobre la solución de conflictos colectivos en Chile, principalmente en lo que dice relación con la institucionalización reciente de las comisiones bipartitas para la implementación y seguimiento del cumplimiento de instrumentos colectivos. En efecto, se identifican elementos fácticos y normativos que permiten hacer un contrapunto entre ambos sistemas normativos.
\end{abstract}

\section{ABSTRACT}

This article analyzes the functional scope of the paritary committees of collective bargaining in the Spanish legal system, focusing the study on the most relevant powers of these committees (with special emphasis on the delimitation between the administration and the negotiation of

\footnotetext{
* Este trabajo ha sido realizado en el marco del Proyecto Anillo "Mecanismos alternativos de resolución de conflictos como herramienta de modernización de la justicia. Construcción dogmática a partir de un análisis multidisciplinario", financiado por Conicyt (SOC 1406).

** Profesor de Derecho del Trabajo, director del Centro de Estudios de Derecho del Trabajo y de la Seguridad Social de la Universidad de Talca, Chile (Centrass). Correo electrónico: rpalomo@utalca.cl.

*** Abogado, licenciado en Ciencias Jurídicas, Universidad de Talca, Chile. Correo electrónico: dvillavicencio.p@gmail.com.
} 
the collective agreement), and the legal effectiveness of its pronouncements in the exercise of its various functions.

The study of the Spanish model brings a contribution to the current debate on the solution of collective conflicts in Chile, mainly in relation to the recent institutionalization of bipartite commissions for the implementation and monitoring of collective instruments compliance. Indeed, factual and normative elements that allows to make a counterpoint between both normative systems are identified.

Palabras Clave

Negociación colectiva, Instrumentos colectivos, Comisiones paritarias, Conflicto colectivo

KEY WORDS

Collective bargaining, Collective instruments, Paritary committees, Collective conflict

\section{Planteamiento preliminar}

No se pretende en esta oportunidad cubrir el extenso manto de cuestiones relacionadas con las comisiones paritarias en el ordenamiento jurídico laboral español; dicha misión, que ha merecido ya la atención -incluso monográficade diversos autores, ciertamente excedería los propósitos y características de este trabajo.

El tema y su enfoque necesariamente debían ser delimitados, y en ese orden de cosas, nos propusimos estudiar el ámbito funcional del referido instituto paritario bajo la vigencia del actual modelo normativo español. El enfoque está centrado, de esta forma, en dar cuenta de las principales comprensiones que se tienen sobre su ámbito de acción y sobre el valor jurídico de sus pronunciamientos, principalmente porque son estos los aspectos que de forma prevalente ocupan la atención de la doctrina, de la jurisprudencia y de los propios convenios colectivos cuando se refieren a estos órganos. Por tanto, aunque sin desconocer su importancia, no se trata en este trabajo la dimensión orgánica de estas comisiones, salvo una referencia a las exigencias de legitimidad que se plantean respecto de su composición, dada la estrecha vinculación de esta cuestión con el enfoque propuesto.

En concreto, se aborda, en primer término y de manera genérica, un breve repaso del contexto teórico en que se ubican los problemas jurídicos indicados, a fin de refrescar las principales discusiones que se han planteado a su respecto. Sobre dicho soporte conceptual centramos luego nuestros esfuerzos en dar cuenta del estado de situación acerca de un par de aristas temáticas que revisten particular interés, tanto dogmático como práctico: por una parte, se analizan las competencias más relevantes de las comisiones paritarias, dando especial énfasis a la todavía compleja delimitación entre la administración y la negociación del convenio colectivo, y al papel de estas comisiones en la solución extrajudicial 
de conflictos laborales, y, por otra parte, se revisa el debate sobre la eficacia jurídica de sus pronunciamientos en el ejercicio de sus distintas funciones.

Ahora bien, de entre las varias perspectivas metodológicas que permiten acercarse a este interesante tema de estudio, hemos seguido un enfoque jurídico eminentemente dogmático, a partir de las publicaciones monográficas y específicas de la doctrina española sobre la materia. Dicho análisis ha sido complementado por la revisión de sentencias representativas (especialmente del Tribunal Constitucional y del Tribunal Supremo) y por el estudio de diversas investigaciones de autores que han examinado la regulación concreta de las comisiones paritarias en convenios colectivos de diversos ámbitos y niveles, a cuya contundencia nos remitimos.

Varias son las razones por las que hemos escogido el modelo español de relaciones laborales como objeto central de este estudio. La primera, de carácter general, radica en la indiscutible influencia que ha ejercido y ejerce dicho modelo normativo sobre nuestro sistema jurídico-laboral, pese a las diferencias que se plantean entre ambas tradiciones jurídicas. Respecto del tema específico sobre que discurre este trabajo, el ordenamiento español aporta amplias y novedosas perspectivas acerca de las fórmulas de solución alternativa de conflictos colectivos, en particular las autocompositivas.

Dado lo anterior, se reflexiona finalmente sobre la situación del ordenamiento jurídico chileno frente a los temas planteados, a fin de ofrecer un contrapunto respecto del análisis del modelo español. Para ello se procura identificar las instituciones que favorecen y potencian un análisis jurídico comparado entre ambos sistemas.

\section{Visión de contexto: Las comisiones paritarias en el ordenamiento jurídico laboral español}

\subsection{Breves antecedentes históricos}

Las comisiones paritarias surgieron como una práctica negocial de generación espontánea, inicialmente carente de reconocimiento legal explícito, principalmente al amparo de las posibilidades de actuaciones que les otorgaba la Ley de Convenios Colectivos de 1958. En esta primera etapa no se les otorgaron, empero, funciones de relevancia.

Su institucionalización con carácter general no se produjo sino hasta la dictación de la Ley de Convenios Colectivos de 1973, que impuso la creación de estas comisiones como contenido necesario de los convenios. Si bien este nuevo marco normativo supuso algún avance para el ámbito funcional de las comisiones paritarias, ellas mantuvieron el rol secundario que caracterizó sus momentos genéticos, dado el marcado intervencionismo que en este periodo 
ejerció la administración laboral en toda la fase de control de legalidad, interpretación y aplicación del convenio.

Esta histórica falta de utilidad práctica de las comisiones paritarias sin duda influyó en la desidia que inicialmente mostraron las partes negociadoras hacia el contenido de su regulación convencional, por una parte, y en una doctrina jurisprudencial cargada de reticencias y prevenciones a la intervención de estos órganos paritarios, por otra.

Posteriormente, la Constitución española de 1978 (en adelante, CE) implantó un nuevo modelo en el ámbito de las relaciones colectivas de trabajo, al reconocer ampliamente la autonomía colectiva y el derecho a la negociación colectiva, modelo que se concretó en el Estatuto de los Trabajadores de 1980 (en adelante, ET). Pues bien, el estudio que se presenta sobre la dimensión funcional de las comisiones paritarias se ha efectuado a partir de este modelo normativo ${ }^{1}$, teniendo presente que tal regulación jurídica se ha visto fuertemente modificada por las reformas acaecidas posteriormente, especialmente las operadas en los años 1994, 2010, 2011 y 2012.

Actualmente, y como resultado de dichos procesos de reforma, las comisiones paritarias se ven caracterizadas por la importancia de sus atribuciones, reconocidas en virtud de la ley o de la convención entre las partes negociadoras. Entre las funciones que son atribuidas al órgano paritario destacan su utilidad como instrumento de adaptación de los contenidos negociados a la realidad cambiante; su función como método idóneo para el desarrollo de mecanismos alternativos de resolución de conflictos colectivos, y su labor de componente dinamizador de las relaciones colectivas del trabajo en contextos de interacción rígida, función que es reforzada por la ley al regularla como contenido mínimo de la negociación².

\subsection{Justificación de las comisiones paritarias en el actual modelo de negociación colectiva español}

Conocida es la distinción que tradicionalmente ha seguido la doctrina entre dos modelos ideales de negociación colectiva: la negociación estática o contractual y la negociación dinámica o permanente ${ }^{3}$. En el primer modelo, las partes se reúnen, negocian, logran el acuerdo y se disgregan hasta que llegue el plazo

\footnotetext{
1 Para una visión histórica del papel de las comisiones paritarias pueden revisarse los trabajos de CRUZ (1985), pp. 205 y ss.; Alemán (1996), pp. 29 y ss.; Morales (1998), pp. 157 y ss.; Feria (2012), pp. 237 y ss., y MONTOYA (2016), pp. 97 y ss.

2 Valdés (2003), p. 37; y García (2016), p. 54.

3 Terminología acuñada por Otto Kahn-Freund en: KAHN-Freund (1987), p. 117.
} 
establecido para reanudar las negociaciones o hasta que deseen modificar lo pactado. En cambio, en el segundo modelo, también Ilamado institucional, las partes crean un órgano permanente, al que encomiendan la función de negociar de manera continua las condiciones de trabajo.

El actual modelo español de negociación colectiva, diseñado originariamente por el Estatuto de los Trabajadores de 1980, sigue respondiendo a un modelo relativamente estático o contractual, anclado fuertemente en la fuerza vinculante que tienen los convenios durante su vigencia, concretizada en diversas manifestaciones del principio de intangibilidad del convenio. Ahora bien, no es menos cierto que dicho modelo ha sido moderado por diversas reformas laborales que han roto con su estricta visión inmovilista, colocándolo en una suerte de espacio de convergencia hacia un modelo más dinámico de negociación. Es el caso, por ejemplo, de la admisión de convenios concurrentes (art. 84 ET), la regulación de los descuelgues previstos en materia de modificación sustancial de condiciones de trabajo (artículo 41.2 ET) y descuelgues o inaplicación en la empresa de condiciones de trabajo previstas en el convenio colectivo aplicable (artículo 82.3 ET), o la designación de una comisión paritaria como contenido mínimo del convenio (artículo 85.3.e ET) ${ }^{4}$.

Con todo, en el escenario normativo actual sigue siendo influyente el modelo estático de negociación colectiva, que distingue la fase de elaboración y negociación del texto del convenio de una fase posterior, de administración y aplicación del mismo. En este panorama, las comisiones paritarias aparecen como un órgano revestido de especial dinamicidad negociadora, protagonista de la aplicación funcional del principal producto de la negociación, el convenio colectivo ${ }^{5}$. Desarrollan, pues, una función eminentemente instrumental, facilitando la ejecución material de lo pactado y sirviendo como medio de apoyo al cumplimiento del régimen convencional ${ }^{6}$, sin perjuicio de las labores de interpretación del convenio colectivo y su rol de etapa prejudicial en caso de conflicto colectivo sobre la aplicación o interpretación de lo negociado.

\subsection{Concepto y principales características}

Entrando ya en el análisis de la configuración jurídica de las comisiones paritarias, cabe señalar que no existe un concepto legal que las defina. No obstante lo anterior, recurriendo a sus elementos distintivos la doctrina las ha definido como "órganos de composición mixta, conformados por representantes

\footnotetext{
4 Tarabini-Castellani (1999), pp. 401 y ss.; Alemán y Rodríguez (2005), p. 258; y García (2016), p. 57.

${ }^{5}$ Cruz (1985), p. 204; y Valdés (2003), pp. 37 y ss.

${ }^{6}$ Alemán (1996), pp. 23 y ss., y Alfonso (2006), pp. 71 y ss.
} 
del banco social y del banco empresarial, que se instituyen en los pactos colectivos con la finalidad de interpretar el convenio, aplicar el clausulado del mismo, y resolver, en su caso, cuantas discrepancias y conflictos surjan durante la vigencia del acuerdo" ${ }^{\prime 7}$.

De esta forma, la definición transcrita pone de relieve el ámbito orgánico de estos institutos (paritarios y representativos), su principal fuente normativa (los pactos colectivos) y el núcleo básico de su ámbito funcional (interpretación y aplicación del convenio, y resolución de conflictos laborales). En efecto, uno de los rasgos más distintivos de estas comisiones es su naturaleza genuinamente convencional, la que se ha traducido en la práctica en una notable polivalencia funcional, pero también en un no menos significativo polimorfismo orgánico de estos órganos ${ }^{8}$.

Ahora bien, en cuanto órganos delegados de la comisión negociadora del convenio, las comisiones paritarias son una manifestación más del principio de autonomía colectiva, contemplado en el artículo 37 CE. Pese a la delegación, es menester adelantar que se trata de dos institutos técnicamente distintos, con una funcionalidad diversa en el proceso de negociación colectiva.

Por último, es relevante destacar que las comisiones paritarias son órganos permanentes y estables durante la vigencia del convenio, que promueven la continuidad de las relaciones entre representantes de los trabajadores y del lado empresarial. En efecto, la constitución de estas comisiones contribuye a garantizar una administración pactada de los convenios colectivos y refuerza los hábitos negociales de los sujetos colectivos durante el proceso de concreción de aquellos ${ }^{9}$. Sin embargo, como consecuencia de su fuente convencional, la grandeza y defecto de las comisiones paritarias radica en la dependencia de su funcionalidad operativa a la credibilidad mostrada a dicha institución por los agentes sociales reunidos en la negociación colectiva, de modo tal que mientras no exista la confianza necesaria en el funcionamiento de dicha institución por parte de los negociadores, no será posible observar el funcionamiento óptimo de las comisiones paritarias en las relaciones colectivas de trabajo ${ }^{10}$.

Con relación a lo anterior, importante es destacar la relevancia que el ordenamiento jurídico español le asigna a la autonomía colectiva en esta materia, por cuanto son las partes negociadoras quienes ostentan la facultad de dotar de funcionalidad y organización a la institución paritaria, lo que les permite

\footnotetext{
7 Alemán (1996), p. 23. Una definición similar se propone en CAvas (2007), p. 116.

${ }^{8}$ Alemán y Rodríguez (2005), p. 261. En este sentido, véase también Ballester y Altés (1996), pp. 316 y ss.

${ }^{9}$ VALDÉS (2003), p. 37.

${ }^{10}$ García (2016), pp. 54 y ss.
} 
adecuar su utilidad y actividad a los intereses colectivos de cada organización. Todo ello a pesar de la intervención legal que ha tenido lugar después de las reformas a la negociación colectiva, intervención que puede ser analizada como perjudicial para la autonomía colectiva, sin perjuicio del deseo de lograr mayor eficiencia en el trabajo del órgano paritario. Nos referiremos a esto más adelante.

\section{Las competencias de las comisiones paritarias}

\subsection{Planteamiento}

El estudio del ámbito funcional de las comisiones paritarias exige el análisis conjunto de las distintas fuentes que lo determinan y la consideración de los criterios jurisprudenciales que han venido concretándolo.

En este sentido, cabe apuntar en primer término que la regulación legal de las comisiones paritarias es exigua y dispersa. Con acierto se ha afirmado que se trata de un régimen indiciario, por cuanto su tratamiento no suele ser objeto de una regulación dedicada exclusivamente a dicho instituto; remisorio en algunos casos e implícito en otros; y siempre inacabado, ya que requiere de la correspondiente concreción en las normas colectivas ${ }^{11}$. Con todo, esta forma de abordar legislativamente la regulación de estas comisiones ha sido valorada positivamente por algunos autores, que ven con buenos ojos que el legislador deje en manos de las partes negociadoras la elección de una "fórmula de mayor o menor intervención de las comisiones paritarias, otorgándoles mayor o menor eficacia a los acuerdos adoptados en su seno"12. No obstante ello, para otros autores la autonomía colectiva pudiera verse resentida por la forma en la que el ordenamiento jurídico ordena la regulación obligatoria del órgano paritario por la comisión negociadora ${ }^{13}$.

Pues bien, uno de los preceptos estatutarios más relevantes sobre estos órganos es el artículo 85.3.e, que establece que forma parte del contenido mínimo de los convenios colectivos la "designación de una comisión paritaria de la representación de las partes negociadoras para entender de aquellas cuestiones establecidas en la ley y de cuantas otras le sean atribuidas, así como establecimiento de los procedimientos y plazos de actuación de esta comisión, incluido el sometimiento de las discrepancias producidas en su seno a los sistemas no

\footnotetext{
11 Alemán (1996), p. 37.

12 Cruz (1985), p. 208.

13 En este sentido, véase González (2013), pp. 283 y ss., y García (2016), pp. 57 y ss.
} 
judiciales de solución de conflictos establecidos mediante los acuerdos interprofesionales de ámbito estatal o autonómico previstos en el artículo 83"14.

El artículo 91.1 ET, por su parte, preceptúa que "sin perjuicio de las competencias legalmente atribuidas a la jurisdicción social, el conocimiento y resolución de las cuestiones derivadas de la aplicación e interpretación de los convenios colectivos corresponderá a la comisión paritaria de los mismos". Importante es destacar que dicha regulación es consecuencia de la reforma introducida por el Real Decreto Ley (en adelante, RDL) 7/2011 -modificado parcialmente en 2015-, que vino a ajustar lo preceptuado por el antiguo artículo 91 ET, al que su confusa redacción le valió sendas críticas doctrinales y provocó diversos problemas interpretativos.

Otro referente normativo es el inciso $3^{\circ}$ del artículo 82.3 ET, sobre descuelgue en la empresa de ciertas condiciones de trabajo previstas en el convenio colectivo aplicable ${ }^{15}$, que se refiere a posibles escenarios de actuación de las comisiones paritarias. En efecto, el citado artículo establece que si el periodo de consultas previas previsto en el procedimiento de inaplicación o descuelgue concluye sin acuerdo, cualquiera de las partes podrá recurrir a la comisión paritaria del acuerdo colectivo para que determine si se cumplen las condiciones de descuelgue o no.

Además de las citadas referencias estatutarias, pueden encontrarse también otras referencias indirectas al papel de estas comisiones. El artículo 85.1 ET, por ejemplo, confiere a los convenios la facultad de establecer los "procedimientos para resolver las discrepancias surgidas en los periodos de consulta previstos en los artículos 40, 41, 47 y 51 de esta Ley". Nada obsta a que, sin excluir otras alternativas, se faculte a la comisión paritaria para resolver dichas discrepancias ${ }^{16}$. Lo mismo ocurre en materia de resolución extrajudicial de conflictos laborales (conciliación y mediación), donde pueden hallarse funciones potenciales de las comisiones paritarias en el apartado 2 del artículo 91 y en los apartados 2 y 3 del artículo 83 ET, y en los artículos 63 y 153.1 de la Ley Reguladora de la Jurisdicción Social (en adelante LRJS). Sobre estas normas se volverá luego.

\footnotetext{
${ }^{14}$ Revísense algunos aspectos relevantes sobre la regulación de las comisiones paritarias en el convenio colectivo en las siguientes sentencias: Tribunal Supremo, STS 5715/2007, de 22 de junio de 2007; Tribunal Supremo, STS 223/2013, de 26 de marzo de 2013, y Tribunal Supremo, STS 5578/2015, de 11 de noviembre de 2015.

15 Tras la reforma a la negociación colectiva realizada en 2012, las materias susceptibles de descuelgue o inaplicación, cuando concurran causas económicas, técnicas, organizativas o de producción, son: jornada de trabajo; horario y distribución de tiempos de trabajo; régimen de trabajo a turnos; sistema de remuneración y cuantía salarial; sistema de trabajo y rendimiento; funciones, y mejoras voluntarias de la acción protectora de la seguridad social.
}

16 Tarabini-Castellani (1999), p. 402. 
Ahora bien, pasando a la dimensión convencional, los convenios colectivos han otorgado, aunque generalmente dispersas en sus textos, amplias y diversas funciones a las comisiones paritarias, al amparo de la propia holgura de la formulación legal del antes transcrito artículo 85.3.e ET, que las faculta para atender "cuantas cuestiones le[s] sean atribuidas".

En efecto, algunos convenios se refieren a las competencias de estas comisiones de manera ambigua o genérica, mientras que otros incluyen cláusulas donde se indican expresamente las distintas funciones que pueden desempeñar. Mientras que la primera opción tiene el riesgo de ver aumentada la conflictividad durante la vigencia del convenio, por la imprecisión de los encargos, la segunda entraña la posibilidad de dejar fuera de su campo de actuación importantes atribuciones. Asimismo, y pese a que como contenido mínimo del convenio se exige la creación de una sola comisión, la práctica negocial demuestra que muchas veces se crean varias comisiones y subcomisiones para atender a los distintos cometidos, generándose un complejo fenómeno de "hibridación funcional"17.

En cualquier caso, cabe adelantar que el ámbito natural de actuación de las comisiones paritarias es el de la administración del convenio colectivo, terreno que tiene como límite material el desarrollo de funciones negociadoras, reservadas en principio a las comisiones negociadoras.

Además del marco legal y convencional previamente presentado, una visión completa del panorama competencial de las comisiones paritarias exige tener en cuenta la delimitación que del mismo han hecho los tribunales. Pese a la amplitud funcional establecida normativamente y recepcionada en general por los convenios, la jurisprudencia constitucional y ordinaria ha reaccionado estableciéndole ciertos criterios y límites. En este sentido, los tribunales también han jugado un papel relevante en la definición de las coordenadas del ámbito material de actuación de estas comisiones.

\subsection{La debatida distinción entre la administración y la negociación del convenio colectivo}

Como se adelantó, existe cierto consenso en que el marco natural de actuación de las comisiones paritarias es el de la administración del convenio colectivo. Sin embargo, la noción de administración del convenio no es unívoca. Frente a la restringida asimilación de su definición con las funciones de interpretación y aplicación del convenio, se plantean también significaciones más amplias, que llegan a agregar a las anteriores todas aquellas actuaciones

\footnotetext{
17 Sobre el tratamiento convencional de las comisiones paritarias, véanse, entre otros, los estudios de Morales (1998), pp. 259 y ss.; Pérez (2002), pp. 199 y ss.; Escudero (2004), pp. 839-855; Montoya (2016), pp. 97 y ss., y HierRo (2016), pp. 26 y ss.
} 
dirigidas al "cuidado o provisión de medios para el mejor logro, aprovechamiento y cumplimiento de determinadas cosas o derechos"18.

Pese a que aquella visión más estrecha parece estar superada, tampoco puede entenderse la administración del convenio como un concepto de tan amplia significación que englobe a todas aquellas actividades que se desarrollen por las partes una vez firmado el mismo, de modo que solo tengan en común el hecho de ejercitarse durante su vigencia. No se puede desconocer que la amplia y diversa gama de funciones que se otorgan a las comisiones paritarias por los convenios colectivos ha puesto de manifiesto que en ocasiones aquellas exceden el ámbito de la administración de los mismos, revistiendo en los hechos una naturaleza negocial ${ }^{19}$.

Dado el modelo de negociación colectiva imperante en España, que reserva estas últimas competencias a los sujetos investidos de la debida legitimación legal (comisión negociadora), los tribunales han debido pronunciarse sobre cuáles son las cuestiones que pueden desarrollar válidamente los órganos paritarios, distinguiendo al efecto entre los actos de administración y los actos de negociación, tarea nada sencilla en las relaciones laborales modernas.

\subsubsection{La tesis del Tribunal Constitucional}

El Tribunal Constitucional fue quien primero marcó la distinción entre actos de administración y actos de negociación del convenio. Los supuestos que se han planteado con mayor frecuencia en la referida sede judicial son los de sindicatos que no han firmado un convenio ni se han adherido a él, pero reclaman luego que su exclusión de las comisiones creadas convencionalmente constituye un atentado a la libertad sindical, específicamente por la vulneración de su derecho a la negociación colectiva. Se ha precisado que estos supuestos podrían producirse también en relación con grupos minoritarios que hayan efectivamente participado en todas las fases de la negociación ${ }^{20}$. En la misma línea, y tal como ha manifestado la doctrina ${ }^{21}$, se debe mencionar que la mayoría de los conflictos colectivos solucionados por la jurisdicción social sobre la naturaleza de las competencias ejercidas por las comisiones paritarias, se producen por la exclusión de esta tarea del órgano paritario a un sujeto colectivo legitimado para negociar, bajo el argumento de que, al no ser firmante del convenio, no puede solicitar su presencia en una institución creada por el mismo convenio.

\footnotetext{
18 GIL (1992), p. 193.

19 GonzÁlez (2007), pp. 119 y ss.

20 Goerlich (1988), p. 2111.

21 En este sentido, véase González (2007), pp. 307 y ss., y García (2016), p. 76.
} 
Para resolver si dichas exclusiones son o no constitutivas de un atentado a la libertad sindical, el referido tribunal ha efectuado el comentado distingo. De este modo, ha señalado que los actos de administración son aquellos que persiguen la interpretación o aplicación de alguna de las cláusulas convencionales, la adaptación de las mismas a un problema no previsto, o la adaptación del contenido del convenio según datos objetivos y prefijados (por ejemplo, un incremento salarial aplicando el IPC). Los actos de negociación, en cambio, son aquellos que modifican las condiciones de trabajo pactadas, estableciendo nuevas normas para regir las relaciones laborales en el ámbito de aplicación del convenio. La distinción, ha precisado el Tribunal Constitucional, no depende del simple enunciado o de la simple descripción de las funciones de las comisiones paritarias, sino que debe efectuarse una valoración sistemática de su regulación convencional y de la lógica que impone en la concreta realidad de las relaciones colectivas.

A partir de la distinción que se comenta, el tribunal reconoce el derecho a participar de las comisiones que desarrollan actos de negociación a todos los sujetos legitimados para negociar colectivamente, hayan o no firmado el convenio respectivo. Lo contrario supondría un quebrantamiento de la libertad sindical, toda vez que se vería afectado el derecho a la negociación colectiva de los sindicatos no firmantes. En cambio, se reserva a las partes firmantes $-y$ por extensión a la comisión paritaria- la legitimación para ejecutar cometidos que caben dentro de la administración del convenio ${ }^{22}$.

En la misma línea, pero referido a la posibilidad de las comisiones paritarias para realizar modificaciones a lo establecido en el convenio, en Tribunal Constitucional presenta una excepción a la tesis general seguida por el Tribunal Supremo ${ }^{23}$, por cuanto la sede constitucional señaló que si bien es cierto que en términos generales las comisiones paritarias no tienen facultades normativas, la prohibición de adjudicarles funciones de modificación del convenio, que sea ciertamente reguladoras del mismo, no rige respecto de aquellas comisiones

\footnotetext{
${ }^{22}$ Véanse al respecto, entre otras, las siguientes sentencias del Tribunal Constitucional: Tribunal Constitucional, STC 12/1983, de 22 de febrero de 1983; Tribunal Constitucional, STC 73/1984, de 27 de junio de 1984; Tribunal Constitucional, STC 9/1986, de 21 de enero de 1986; Tribunal Constitucional, STC 39/1986, de 31 de marzo de 1986; Tribunal Constitucional, STC 187/1987, de 24 de noviembre de 1987; Tribunal Constitucional, STC 184/1991, de 30 de septiembre de 1991; Tribunal Constitucional, STC 213/1991, de 11 de noviembre de 1991, y Tribunal Constitucional, STC 222/2005, de 12 de septiembre de 2005. Véase también el trabajo de GarRIGUES (1998), pp. 119 y ss.

${ }^{23}$ La jurisdicción social viene negando la posibilidad de las comisiones paritarias de dictar normas, argumentando que el convenio colectivo no está facultado para delegar funciones normativas en las comisiones. Véanse las sentencias: Tribunal Supremo, STS 3066/2014, de 1 de abril de 2014; Tribunal Supremo, STS 407/2015, de 3 de febrero de 2015; Tribunal Supremo, STS 8360/1994, de 15 de diciembre de 1994, y Tribunal Supremo, STS 6665/1991, de 27 de noviembre de 1991.
} 
que estén abiertas a un sindicato legitimado para negociar, aunque no hayan firmado el convenio ni adherido a él, pero cumpliendo con la legitimación de su composición para negociar el convenio que pretenden modificar, asunto que el RDL 7/2011 reguló de forma expresa ${ }^{24}$.

Así las cosas, el Tribunal Constitucional concluye que si las comisiones paritarias -o las subcomisiones creadas para ese efecto- están compuestas por los mismos sujetos colectivos que pueden negociar el convenio, y teniendo derecho a integrarse incluso los sujetos colectivos que se negaron a su suscripción, dicha comisión paritaria tendrá facultades reguladoras o normativas respecto a las atribuciones señalas en la ley o en el mismo convenio. Fuera de este supuesto, la institución paritaria carecería de la legitimidad necesaria para cumplir dichas funciones normativas y reguladoras ${ }^{25}$.

\subsubsection{Las líneas jurisprudenciales del Tribunal Supremo}

El Tribunal Constitucional agota su competencia en la resolución de la existencia o no de vulneraciones a la libertad sindical en los supuestos indicados, mas no entra a valorar la legalidad de las cláusulas convencionales que asignan a las comisiones paritarias funciones que revisten carácter negocial, o de los actos que se realizan a su amparo, juicio que corresponde a los tribunales de la jurisdicción ordinaria.

Para efectuar el referido juicio de legalidad, los tribunales ordinarios han echado mano a la exégesis efectuada inicialmente por el Tribunal Constitucional, distinguiendo también entre actos de administración y actos de naturaleza negocial. Así las cosas, la jurisprudencia ha venido entendiendo que estos últimos, para tener eficacia normativa, deben respetar las normas estatutarias sobre el procedimiento de negociación, la fuerza normativa del convenio y la vigencia del mismo. De lo contrario, merecen la calificación de nulidad ${ }^{26}$.

Más allá de la dicotomía conceptual defendida jurisprudencialmente, la frontera entre los actos de administración y de negociación suele no presentarse diáfana en la práctica. Por ello, particular relevancia tiene la labor de los tribunales ordinarios en la delimitación del propio concepto de administración

\footnotetext{
${ }^{24}$ Roldán (2014), pp. 212-213.

25 Posición adoptada en las siguientes sentencias: Tribunal Constitucional, STC 184/1991, de 30 de septiembre de 1991; Tribunal Constitucional, STC 73/1984, de 27 de junio de 1984; Tribunal Constitucional, STC 39/1986, de 31 de marzo de 1986; Tribunal Supremo, STS 524/2000, de 28 de enero del año 2000; Tribunal Supremo, STS 3775/2011, de 9 de mayo del año 2001, y Tribunal Supremo, STS 5304/2013, de 21 de octubre de 2013.
}

26 Montoya (2016), p. 104. 
del convenio colectivo. En ellos reside, en último término, la decisión sobre la naturaleza jurídica de las funciones y actuaciones de las comisiones paritarias ${ }^{27}$. Inicialmente, la jurisprudencia ordinaria interpretó de manera especialmente restrictiva los cometidos que podían desarrollar las comisiones paritarias. En efecto, la primera jurisprudencia que se refirió al entonces artículo 85.2.d ET (actual artículo 85.3.e ET) circunscribió dichas funciones a las de interpretación y aplicación del convenio ${ }^{28}$.

Posteriormente, aunque sin superar su visión estrecha sobre el papel de las comisiones en estudio, los tribunales han matizado su interpretación inicial y en general entienden que dentro de las competencias que pueden desempeñar válidamente estas comisiones caben todas aquellas que no supongan una modificación de las condiciones de trabajo pactadas en el convenio o el establecimiento de nuevas normas. De esta forma, las comisiones paritarias pueden desempeñar todas las funciones que convencionalmente se les confíen, siempre que no invadan, bajo apariencia de administración del convenio, esferas propias de la regulación ${ }^{29}$.

A partir de un análisis taxonómico de la doctrina judicial se han identificado al menos tres parámetros que inducen a considerar que una determinada función de una comisión paritaria tiene naturaleza negocial: la manera en que, terminológicamente, aparece formulada la competencia en cuestión en el convenio; la proyección general o normativa de la misma, y el hecho de exceder

27 Cavas (2007), p. 126.

${ }^{28}$ Véase una relación de la evolución de la jurisprudencia ordinaria en TARABINI-CASTELLANI (1999), pp. 389 y ss.

${ }^{29}$ De entre los múltiples pronunciamientos del Tribunal Supremo sobre estas materias, véanse a modo ejemplar las siguientes sentencias: Tribunal Supremo, STS 2832/1991, de 30 de mayo de 1991; Tribunal Supremo, STS 6665/1991, de 27 de noviembre de 1991; Tribunal Supremo, STS 938/1992, de 10 de febrero de 1992; Tribunal Supremo, STS 2589/1992, de 25 de marzo de 1992; Tribunal Supremo, STS 5068/1992, de 24 de junio de 1992; Tribunal Supremo, STS 12856/1993, de 28 de enero de 1993; Tribunal Supremo, STS 3363/1993, de 25 de mayo de 1993; Tribunal Supremo, STS 3605/1995, de 20 de junio de 1995; Tribunal Supremo, STS 3409/1996, de 4 de junio de 1996; Tribunal Supremo, STS 7379/1996, de 19 de diciembre de 1996; Tribunal Supremo, STS 4629/1999, de 29 de junio de 1999; Tribunal Supremo, STS 4934/1999, de 9 de julio de 1999; Tribunal Supremo, STS 524/2000, de 28 de enero de 2000; Tribunal Supremo, STS 5729/2000, de 11 de julio de 2000; Tribunal Supremo, STS 9142/2000, de 12 de diciembre de 2000; Tribunal Supremo, STS 2882/2001, de 5 abril de 2001; Tribunal Supremo, STS 3775/2011, de 9 de mayo del año 2001; Tribunal Supremo, STS 4310/2001, de 24 de mayo de 2000; Tribunal Supremo, STS 8443/2011, de 30 de octubre de 2001; Tribunal Supremo, STS 1805/2002, de 13 de marzo de 2002; Tribunal Supremo, STS 3475/2004, de 20 de mayo de 2004; Tribunal Supremo, STS 1672/2005, de 16 de marzo de 2005; Tribunal Supremo, STS 7665/2005, de 31 de octubre de 2005; Tribunal Supremo, STS 2958/2006, de 8 de marzo de 2006; Tribunal Supremo, STS 4004/2010, de 25 de junio de 2010; Tribunal Supremo, STS 4234/2015, de 14 de septiembre de 2015, y Tribunal Supremo, STS 1463/2018, del 4 de abril de 2018. 
las atribuciones contenidas en el acto de delegación ${ }^{30}$. Ninguno de los citados presupuestos basta por sí solo para reconocer carácter negocial a una competencia, ni tampoco la conjunción de ellos garantiza dicha calificación, empero han venido constituyendo importantes pautas hermenéuticas para dicho cometido.

Con todo, si bien la jurisprudencia-constitucional y ordinaria- ha diseñado un marco general de cara a la solución de estos problemas, la concreción de la distinción entre actos de administración y de negociación siempre supondrá una compleja respuesta casuística ${ }^{31}$.

\subsubsection{Posiciones doctrinales}

En general, la doctrina laboralista española concuerda con la distinción entre actos de administración y actos de negociación a efectos de calificar la legalidad y validez de las distintas funciones que desempeñan las comisiones paritarias. Sin embargo, aunque sin desconocer de plano dicha tesis, un sector doctrinal la asume con recelo, ya sea porque cuestionan la concreta delimitación jurisprudencial entre administración y negociación, ya sea porque estiman que las comisiones paritarias pueden ostentar ciertas capacidades de dimensión negocial.

En efecto, algunos autores han puesto de relieve la estrechez con que los tribunales vienen entendiendo la administración del convenio, aun cuando admiten que hay una cierta tendencia a reconocer una mayor laxitud de dicha función ${ }^{32}$. También se ha criticado que la distinción respecto de los actos negociales se haya venido planteando por los tribunales con notable ambigüedad e imprecisión, haciéndola artificiosa y dejando amplio margen a zonas grises de difícil calificación. En este sentido, en el afán de desentrañar el significado de las labores de administración y negociación, a menudo los tribunales han generado mayor conflictividad que la que se deriva de los propios términos ${ }^{33}$.

Por otro lado, se ha reivindicado una cierta dimensión negocial de las comisiones paritarias, a partir de la desmitificación de que el desarrollo de

\footnotetext{
30 Alemán y RodríGuez (2005), p. 288. diferentes materias.

32 Alemán (2001), p. 57, y Alfonso (2006), p. 75.

33 Morales (1998), pp. 109 y ss., y Rodrícuez (2006), p. 117.
}

${ }^{31}$ Estudios del variopinto repertorio jurisprudencial pueden revisarse en: GARRIGUES (1998), pp. 118 y ss.; TARABINI-CAstellani (1999), pp. 396 y ss., y Alemán y RodríGuez (2005), pp. 283 y ss. Estos últimos Ilaman a este enfoque casuístico "fabricación reflexiva", toda vez que debe considerar la complejidad intrínseca de las funciones de las comisiones paritarias, su carácter abierto, dependiente de la propia dinámica sindical y conectada con la extrajudicialidad en su globalidad, y las sinergias entre las 
funciones de esta naturaleza se reduzca en todo caso a una modificación de lo pactado. La administración del convenio, se ha afirmado, no forma parte de un universo separado y estanco de la negociación, sino que se configura como una "prolongación, en otro escenario y a través de otras técnicas, de la actividad negociadora una vez estipulado el convenio" ${ }^{\prime 34}$.

A mayor abundamiento, se ha puesto de manifiesto que las reformas al Estatuto de los Trabajadores han modificado el contexto normativo de la negociación colectiva, en general, y han ampliado sustancialmente el ámbito competencial de las comisiones paritarias, en particular al punto de legitimarlas legalmente para regular condiciones de trabajo, incluso apartándose del clausulado convencional, siempre que se den las circunstancias estatutarias para que dicha modificación tenga lugar ${ }^{35}$. Concretamente, esta dimensión negocial se reconoce al instituto paritario respecto de las materias específicas a que se refieren los artículos 41.2 y 82.3 ET, ya mencionados, y también se haría patente en el potenciamiento del rol de estas comisiones dentro de los sistemas de solución autónoma de conflictos laborales.

En la misma línea, y asumiendo el riesgo de desvirtuar la prístina naturaleza del ente paritario, se ha sostenido que no merece reproche jurídico el que las partes negociadoras atribuyan a la comisión paritaria facultades de desarrollo normativo o de revisión parcial de lo pactado, siempre que se cumplan los indisponibles requisitos legales de legitimación, inicial y plena, y los procedimientos previstos en el Estatuto de los Trabajadores (si se quiere que la negociación sea estatutaria $)^{36}$.

\section{Las funciones básicas de las comisiones paritarias}

La interpretación, aplicación y vigilancia del convenio colectivo (administración del convenio en sentido estricto) son las funciones que típicamente se han venido confiriendo a estos órganos paritarios, de manera que conforman el núcleo funcional básico de los mismos.

\footnotetext{
${ }^{34}$ VALDÉS (2003), p. 40. En este sentido, véase también GarCía (2016), p. 76.

35 Tarabini-Castellani (1999), p. 403.

36 En este sentido: Cruz (1985), pp. 221-222; Cavas (2007), p. 127, y Montoya (2016), p. 105. Algunas sentencias han seguido esta tesis. Véanse, por ejemplo, las sentencias del Tribunal Supremo: Tribunal Supremo, STS 4934/1999, de 9 de julio de 1999; Tribunal Supremo, STS 4004/2010, de 25 de junio de 2010; Tribunal Supremo, STS 407/2015, de 3 de febrero de 2015; Tribunal Supremo, STS 4234/2015, de 14 de septiembre de 2015, y Tribunal Supremo, STS 2131/2017, de 11 de marzo de 2017, y las sentencias de la Audiencia Nacional: Audiencia Nacional, SAN 664/2018, de 2 de marzo de 2018, y Audiencia Nacional, SAN 5174/2017, de 27 de diciembre de 2017.
} 


\subsection{La función interpretativa}

Como se adelantaba en el apartado anterior, uno de los mayores problemas que plantea el ámbito funcional de las comisiones paritarias es la falta de certeza jurídica respecto de los deslindes de sus distintas competencias. En efecto, la multiplicidad y complejidad de las funciones atribuidas a estas comisiones ha forzado a que su delimitación se realice luego del análisis y valoración de cada supuesto concreto.

Esta dificultad delimitadora no es ajena a la función de interpretación del convenio que pueden desarrollar las comisiones paritarias. Especialmente compleja ha resultado la distinción respecto de aquellos actos que importan una modificación del convenio colectivo y que, por tanto, rebasan la mera interpretación ${ }^{37}$.

En el ánimo de aclarar esta nebulosa conceptual, cabe tener presente que la interpretación supone en último término esclarecer, mediante una declaración de voluntad, el sentido y alcance de una o varias cláusulas concretas de un determinado convenio colectivo, sin alterar la situación jurídica preexistente. La necesidad de interpretar, por su parte, puede encontrar diversas causas: el texto del convenio es confuso o incompleto; hay enunciados excesivamente amplios, ambiguos o polisémicos; se utilizan ciertos conceptos jurídicos indeterminados; hay cláusulas descontextualizadas por cambios en las circunstancias; se incorporan acuerdos no auténticos o compromisos apócrifos, etc. Por lo demás, no es extraño que este tipo de formulaciones sean más o menos intencionadas por las propias comisiones negociadoras que, en aras a facilitar la firma del convenio, difieren temporalmente los eventuales $\operatorname{conflictos}^{38}$.

En este punto cabe precisar también que la actividad interpretativa de la comisión paritaria no exige, como requisito sine qua non, el planteamiento explícito de un conflicto jurídico, aunque generalmente son dichas situaciones las que subyacen a la intervención de la comisión. Por el contrario, se ha señalado con acierto que la función en comento se concreta a menudo en una actividad interpretativa abstracta y de alcance general, cuyo carácter le otorga la "virtualidad profiláctica" de contribuir directamente, si bien de un modo incidental, a evitar posibles situaciones controvertidas que pudieran, en un futuro, plantearse de no haber procedido previamente a la clarificación y/o concreción de determinados extremos ${ }^{39}$.

37 Para una visión casuística de las facultades de interpretación del convenio, véase TARABINI-CASTELLANI (1999), pp. 393 y ss.

38 Alemán (2001), p. 80; Alemán y Rodríguez (2005), p. 258, y Cavas (2007), p. 115.

${ }^{39}$ Garrigues (1998), p. 116. 
Del mismo modo, conviene poner de relieve que además de la interpretación general que hagan las comisiones paritarias de un convenio colectivo, estas podrán también efectuar interpretaciones de carácter particular, o interpretaciones aplicativas, para determinar hasta qué punto una concreta situación de hecho puede ser subsumida en el clausulado previsto en un convenio.

La labor hermenéutica de las comisiones paritarias, a más de las reglas que regulan la exégesis convencional, tiene dos límites externos, cuya transgresión faculta para la revisión judicial del acuerdo. En primer término, la interpretación del órgano paritario debe sumisión al mandato recibido del propio convenio, cuya amplitud queda limitada, a su vez, a no invadir funciones de naturaleza negocial. Asimismo, en el ejercicio de esta labor la comisión debe tener muy en cuenta el texto gramatical que se interpreta ${ }^{40}$. Sobre este último, hay cierto consenso en la doctrina en cuanto a la primacía de la voluntad declarada frente a la voluntad interna de las partes contratantes, aun cuando esta tenga especial relevancia dada la doble naturaleza - de contrato y norma- de los convenios colectivos en el sistema jurídico español ${ }^{41}$.

\subsection{La función aplicativa}

Esta función también es de controvertida delimitación, dada la ausencia de un concepto indiscutido que permita conocer cuáles son las tareas que puede realizar la comisión paritaria en aplicación del convenio. Sin embargo, existe cierto consenso en que esta función se manifiesta en todas aquellas actividades necesarias para la gestión y materialización de aquellos aspectos regulados en el convenio, al punto de hacer de la comisión paritaria una instancia ejecutiva de lo pactado en su respectivo ámbito de aplicación. En este orden de cosas, se la ha definido como aquella que consiste en "adecuar el convenio a la realidad social ante situaciones de orden colectivo al margen de toda exteriorización litigiosa" ${ }^{42}$.

Tanto la interpretación como la aplicación forman parte de un mismo proceso, de realización o concreción normativa, mas son operaciones diferentes. Mientras que la interpretación consiste básicamente en determinar la recta inteligencia de un enunciado normativo, la aplicación importa la puesta en práctica de la norma conforme al sentido previamente determinado. De esta manera, la aplicación del convenio es una actividad subsiguiente a la interpretación de

\footnotetext{
40 OJEDA (2003), pp. 795-795.

${ }^{41}$ Tarabini-Castellani (1999), pp. 309 y ss.

42 Alemán (2001), p. 81.
} 
este, dirigida a determinar los efectos y consecuencias jurídicas que produce una cláusula determinada, una vez desentrañado su sentido.

Sin embargo, parte de la doctrina identifica la conjunción de las labores de interpretación y aplicación con la administración del convenio colectivo. En efecto, se ha entendido que la función de administración del convenio se configura como la mezcla de las labores de interpretación y aplicación del mismo, función que tiene por fin adaptar los contenidos negociados a problemas no previstos entre las partes, mediante una actuación interna dirigida a adecuar la voluntad negocial a las circunstancias no previstas en el convenio. De tal forma, la comisión paritaria se convierte en una institución cuyo objetivo es la aplicación funcional posterior del acuerdo, pero siempre en relación con los contenidos negociados ${ }^{43}$. A consecuencia de ello, la actividad de las comisiones paritarias busca completar el acuerdo sin innovarlo ni modificar su contenido normativo, de modo que la interpretación y aplicación del convenio constituyen las funciones genuinas de la institución paritaria ${ }^{44}$.

De cualquier forma, es común que los convenios colectivos utilicen indistintamente la fórmula "interpretación y aplicación" para referirse en general al conjunto de actos a que se somete la norma colectiva para regular las concretas relaciones laborales. Lo cierto es que la imprecisión que rodea a estas funciones, ya desde la propia teoría general de las normas, influye en la difícil distinción entre administración y negociación ${ }^{45}$.

\subsection{La función de vigilancia}

Por último, cabe hacer mención de otra de las funciones medulares de las comisiones paritarias: la función de vigilancia o seguimiento del convenio. Esta consiste básicamente en velar por el cumplimiento de los compromisos adquiridos en el convenio colectivo, teniendo la comisión competencia para articular respuestas oportunas en caso de incumplimiento del mismo. En efecto, consiste en una interpelación a los componentes de la comisión para que mantengan una postura activa ante los posibles incumplimientos del pacto y, consiguientemente, denuncien las violaciones del mismo ante la otra parte o ante los órganos competentes, administrativos o judiciales ${ }^{46}$.

\footnotetext{
43 González (2007), p. 305, y García (2016), p. 73.

44 Aleman y Rodriguez (2005), pp. 285 y ss.; Cavas (2007), pp. 125 y ss., y García (2016), p. 74.

45 Sobre la estrecha y controvertida relación entre la interpretación y la aplicación del convenio, véanse VAldÉs (2003), pp. 46-47; MATEOs (2004), pp. 258 y ss., y RodRíGuez (2006), pp. 306 y ss.

46 Alemán (2001), p. 81.
} 


\section{Otras funciones}

Además de las ya comentadas funciones básicas de las comisiones paritarias, se ha ido extendiendo la práctica convencional de encargarles otros cometidos, múltiples y diversos, al amparo de su reconocimiento legal, hoy contenido en el artículo 85.3.e ET. Este amplio abanico funcional ha provocado problemas, como señalamos, cuando entra en el radio reservado a la función normativa, por ejemplo, facultando a las comisiones para establecer nuevos grupos o categorías en el modelo de clasificación profesional vigente; para revisar parcialmente aspectos específicos del convenio, como pueden ser los salarios, sin limitarse a aplicar criterios objetivos y previamente estipulados, o para regular determinadas materias de seguridad social ${ }^{47}$.

Entre las tan diversas funciones que se les confían a las comisiones paritarias en el panorama convencional actual, hay las que dicen relación con la productividad, formación y promoción profesional; encuadramiento profesional, valoración y retribución; reclamaciones, entre otras ${ }^{48}$. En el mismo sentido, se sostiene que, bajo la regulación legal actual, los convenios colectivos pueden atribuir -y así lo hacen en la práctica negocial- nuevas funciones a las comisiones paritarias, no solo para complementar y desarrollar las competencias reconocidas por la ley, sino para añadir otras no contempladas por ellas (funciones de control y vigilancia, de aprobación de reglamentos internos, estudio de las relaciones laborales abarcadas por el convenio y su aplicación concreta, creación de subcomisiones $)^{49}$.

También se les encomiendan funciones de información, consulta, estudio y asesoramiento, tanto para la preparación de futuras negociaciones como para poner de manifiesto la opinión de la comisión sobre la viabilidad de la aplicación de lo convenido ante las más diversas situaciones reales del presente. Asimismo, pueden desempeñar funciones de adaptación de específicas condiciones de trabajo, y especialmente de aquellas que hacen eco de las posibilidades legales de acción en materia de descuelgues o inaplicación de convenio ${ }^{50}$.

Los órganos paritarios pueden desempeñar también un importante papel en la gestión y vigilancia de los compromisos de empleo, constituyéndose en una

\footnotetext{
${ }^{47}$ Véase una relación de diversas funciones normativas que se han atribuido a las comisiones paritarias por los convenios colectivos en Ballester y Altés (1996), p. 315; Morales (1998), pp. 261 y ss., y Mateos (2004), pp. 269 y ss.

48 Alemán (2001), pp. 46 y ss.

49 Montoya (2016), p. 106.

${ }^{50}$ Ballester y Altés (1996), pp. 312-313.
} 
suerte de sustitutos del libre criterio o valoración empresarial en estas materias, y denunciando eventuales incumplimientos ${ }^{51}$.

Particular relevancia cabe reconocer, por último, al rol que se les encarga a las comisiones paritarias en materia de resolución extrajudicial de los conflictos que surgen durante la vigencia del convenio, como consecuencia de su interpretación o aplicación.

\section{El rol de las comisiones paritarias en la solución de conflictos laborales}

La solución extrajudicial de conflictos es una materia íntimamente ligada, en una relación medio-fin, a la labor hermenéutica de las comisiones paritarias, ya que al interpretar las cláusulas del convenio se solventan las discrepancias surgidas en torno a ellas y se evita la judicialización del conflicto. En efecto, la mediación, la conciliación y el arbitraje son instrumentos para poder dar cumplimiento al objeto primordial de estas comisiones -la interpretación del convenio- en supuestos de conflictos laborales principalmente de carácter colectivo ${ }^{52}$.

Coherentemente con lo anterior, y a consecuencia de lo prescrito por el artículo 91.1 ET, se destaca la función cuasijudicial, pero extrajudicial, de resolver problemáticas surgidas a propósito de la interpretación y aplicación del convenio colectivo. De esta forma, se le otorga al órgano paritario funciones eminentemente jurídicas que pueden ser ejercidas tanto en conflictos colectivos como individuales, cuando las partes del litigio se sometan expresamente al procedimiento de la comisión ${ }^{53}$.

\subsection{Formas de intervención de las comisiones paritarias}

La práctica convencional demuestra que es común encargar estos cometidos a las comisiones paritarias, ya sea a la comisión central del convenio, ya sea creando una subcomisión ad hoc ${ }^{54}$.

De los tres procedimientos típicos de resolución alternativa de conflictos (mediación, conciliación y arbitraje), algunos convenios se decantan por uno de ellos, la mayoría combinan dos, y hay también los que hacen una referencia

\footnotetext{
${ }^{51}$ Un interesante estudio sobre este tema se presenta en SERRANo (2003), pp. 163 y ss. Para analizar las distintas funciones otorgadas por los convenios a las comisiones paritarias, véase también el trabajo más reciente de Hierro (2016), p. 34.

${ }^{52}$ Véase al respecto: Ballester y Altés (1996), p. 311, y Sala y Albiol (2002), p. 336.

53 Montora (2016), p. 102.

54 Arrieta (2014), p. 220.
} 
genérica a los tres. En cualquier caso, la conciliación es la fórmula convencional más utilizada ${ }^{55}$.

Las principales ventajas de la intervención de las comisiones paritarias en la resolución extrajudicial de conflictos laborales derivan de su carácter de órganos delegados de la comisión negociadora, lo que confiere un presupuesto de legitimidad operativa a las decisiones que adoptan y las sitúa en una posición de inmejorable cercanía a la controversia. Asimismo, dicho carácter les permite ejercer un papel de autocomposición pasiva, toda vez que su sola existencia predispone el acercamiento entre las partes ${ }^{56}$.

Ahora bien, la misma proximidad al litigio puede jugar en contra en algunas ocasiones, como cuando los componentes de la comisión pierden la necesaria neutralidad en supuestos de arbitraje. Además, el carácter mixto y paritario de estos comités suele reproducir el mismo equilibrio de fuerzas de la comisión negociadora, lo que puede complicar la toma de acuerdos y la eficacia real de los mismos una vez alcanzados.

Por ello es importante que los convenios concreten el mandato del artículo 85.3.e ET, en orden a incorporar el sometimiento de las discrepancias producidas en el seno de la comisión paritaria a los sistemas no judiciales de solución de conflictos establecidos mediante los acuerdos interprofesionales de ámbito estatal o autonómico. Algunas de estas fórmulas han consistido en contemplar la participación de sujetos ajenos y neutrales a la comisión o en articular comités paritarios en niveles superiores al ámbito geográfico del conflicto ${ }^{57}$. El artículo 4.1 del V Acuerdo sobre Solución Autónoma de Conflictos Laborales, de 2012 (ASAC V) ${ }^{58}$, por ejemplo, faculta al Servicio Interconfederal de Mediación y Arbitraje (SIMA) para mediar en los conflictos colectivos de interpretación y aplicación, sin perjuicio de la intervención de las comisiones paritarias, y en las controversias en las comisiones paritarias de los convenios colectivos que conlleven el bloqueo en la adopción de acuerdos, para la resolución de las funciones que legal o convencionalmente tengan atribuidas.

\footnotetext{
${ }^{55}$ Véanse a este respecto los estudios de Alfonso (1993), pp. 14-19; Mateos (2004), pp. 271 y ss., y Alemán y Rodríguez (2005), pp. 288 y ss.

56 AlEMÁN (2001), p. 59.

57 Alemán (2001), pp. 115 y ss. El estudio de los convenios evidencia, sin embargo, que dicha exigencia legal ha sido en general desatendida por la negociación colectiva. Véanse, en este sentido, BALLESTER y Altés (1996), pp. 307, 321 y ss.; Pérez (2002), p. 201, y Hierro (2016), p. 38.

${ }^{58}$ FundaCión Sima (2012).
} 


\subsection{La actuación de las comisiones paritarias como gestión preprocesal en caso de conflicto laboral}

La eventual obligatoriedad de actuación de la comisión paritaria, previa a la actuación de los órganos jurisdiccionales, ha sido punto de constante debate en la doctrina ibérica. En efecto, existe una importante labor interpretativa de la normativa que regula la materia y de la cual depende la potencial importancia de las comisiones paritarias como etapa previa -y obligatoria- a la jurisdiccional. Haciendo un escueto análisis de la regulación, se puede mencionar al artículo 91.3 ET, que dispone que "en los supuestos de conflicto colectivo relativo a la interpretación o aplicación del convenio deberá intervenir la comisión paritaria del mismo con carácter previo al planteamiento formal del conflicto en el ámbito de los procedimientos no judiciales a que se refiere el apartado anterior o ante el órgano judicial competente". A primera vista, se podría concluir que la participación de la comisión paritaria como etapa previa y extrajudicial es requisito obligatorio para acceder, en caso de disconformidad con el resultado, ante la jurisdicción social.

Sin embargo, se debe tener también en cuenta lo prescrito por los artículos 156 y 63 LRJS. El primero de ellos establece que será requisito necesario, para la tramitación del proceso de conflicto colectivo, el intento de conciliación o mediación en los términos previstos en el artículo 63 del mismo cuerpo legal. Dicha norma identifica como instancias de conciliación o mediación tanto al servicio administrativo como a los sistemas extrajudiciales de solución de conflictos, sin mencionar a la comisión paritaria, por lo que, de no haber acuerdo en el órgano paritario sobre el conflicto que le sea presentado, las partes deberán recurrir a otro mecanismo, previo a la etapa jurisdiccional, para cumplir con el requisito procesal necesario para acudir a tribunales.

Sin perjuicio de lo anterior, es la misma disposición legal la que podría ofrecer a la comisión paritaria el ejercicio de dicha función prejudicial. En efecto, el mencionado artículo dispone la posibilidad de que quien cumpla esa labor sea "el órgano que asuma estas funciones que podrá constituirse mediante los acuerdos interprofesionales o los convenios colectivos a los que se refiere el artículo 83 del Texto Refundido de la Ley del Estatuto de los Trabajadores (...)".

Para algunos autores, la combinación de los artículos 91.3 ET, y 156 y 63 LRJS desmiente que la intervención de la comisión paritaria tenga eficacia para dar por cumplido el requisito de conciliación previa, bajo la consideración de que este órgano no constituye un órgano externo al conflicto ${ }^{59}$. De esta manera,

59 García (2016), p. 72. 
el fracaso de la comisión en la solución del conflicto no agotaría ningún trámite procesal previo a la intervención de los tribunales ${ }^{60}$.

Para otros, la contundente fórmula del artículo 91.3 ET impone claramente, y sin necesidad de intervención del convenio colectivo, el obligado cumplimento del trámite dispuesto, en orden a la participación previa de la comisión paritaria en el conflicto ${ }^{61}$.

Más allá de la discusión doctrinal, es habitual que las partes negociadoras acuerden la necesidad de que la comisión paritaria sea utilizada siempre de manera previa a la intervención judicial, supliendo así el trámite procesal de conciliación previa al que se refieren los artículos 156 y 63 LRJS. De esta forma, son muchos los convenios que establecen la intervención de las comisiones paritarias, generalmente a través de la conciliación y la mediación, como exigencia previa a la actuación de los órganos jurisdiccionales en caso de conflicto laboral (principalmente de naturaleza colectiva) ${ }^{62}$.

Ahora bien, la jurisprudencia ha venido señalando sostenidamente que la actuación de los institutos paritarios, en la composición de estos conflictos, tiene carácter obligatorio solo cuando así se prevée expresa y claramente en el convenio respectivo, sin que ello signifique una vulneración del derecho a la tutela judicial, consagrado en el artículo $24 \mathrm{CE}^{63}$. En efecto, estas actuaciones no son sino una manifestación de la autonomía colectiva y, más concretamente, del derecho a la negociación colectiva y a adoptar medidas eficientes de solución de conflictos colectivos. Ello siempre que no se vea afectada la competencia de los órganos jurisdiccionales ni el ejercicio del derecho de los trabajadores a presentar acciones judiciales, contemplado en el artículo 4.2.g ET ${ }^{64}$, cuestiones sobre las que volveremos al analizar el valor jurídico de los pronunciamientos de las comisiones paritarias.

Aplicando en el sentido inverso el mismo criterio jurisprudencial, solo podrá estimarse como voluntario el recurso a las comisiones paritarias en los casos en

${ }^{60}$ Cruz (1985), pp. 268 y ss., y González (2007), p. 304.

${ }^{61}$ Montora (2016), p. 103.

62 Ballester y Altés (1996), pp. 312, 327 y ss.

${ }_{63}$ Revísese la sentencia del Tribunal Constitucional, STC 217/1991, de 14 de noviembre de 1991. En la jurisprudencia ordinaria esta tesis ya había sido sostenida por el extinto Tribunal Central de Trabajo, por ejemplo en sentencias de 7 de febrero, 8 y 29 de marzo, 5 de abril y 9 de mayo de 1989. Véanse también, entre otras, las sentencias del Tribunal Supremo: Tribunal Supremo, STS 2589/1992, de 25 de marzo de 1992; Tribunal Supremo, STS 7211/1994; Tribunal Supremo, STS 7219/1994, de 8 de noviembre de 1994, Tribunal Supremo, STS 6398/1997, de 28 de octubre de 1997, y, más recientemente, la sentencia de la Audiencia Nacional, SAN 4207/2017, de 26 de octubre de 2017.

${ }^{64}$ Sentencias del Tribunal Supremo: Tribunal Supremo, STS 1909/1996, de 27 de marzo de 1996, y Tribunal Supremo, STS 5223/1996, de 2 de octubre de 1996, entre otras. 
que no se prevea concluyentemente su intervención previa y preceptiva. Por ello, es particularmente relevante que los convenios no se limiten a realizar declaraciones genéricas al regular las funciones y procedimientos de actuación de las comisiones paritarias, toda vez que ello significa una importante merma en su operatividad ${ }^{65}$.

Por otra parte, se ha consolidado el criterio jurisprudencial que estima que la falta de agotamiento de dicho trámite preprocesal no fundamenta la interposición de un recurso de casación, toda vez que con ello no se afecta ninguna norma sustantiva ni se comete ninguna infracción procesal relevante, que sea determinante de indefensión ${ }^{66}$.

Por último, cabe señalar que, aunque no sea una práctica generalizada, se plantean problemas similares cuando la intervención paritaria previa se prevé respecto de cualquier medida de conflicto colectivo, incluida la huelga ${ }^{67}$.

\subsection{Articulación con los acuerdos interprofesionales estatales y autonómicos de resolución de conflictos}

Entre los sistemas de solución extrajudicial de conflictos laborales se cuentan, por un lado, aquellos fijados por los propios convenios colectivos, en los que se atribuye preferentemente a las comisiones paritarias el carácter de órganos de composición de las controversias que surjan en su aplicación e interpretación, y, por otro, los mecanismos derivados de los acuerdos interprofesionales, externos al ámbito de los convenios específicos y con competencias potenciales para resolver todos los conflictos posibles, no solo los de interpretación y aplicación del convenio ${ }^{68}$.

Pues bien, la tendencia es a integrar la función compositiva desarrollada por las comisiones paritarias en los sistemas extrajudiciales de solución de conflictos laborales creados por los acuerdos interprofesionales, tanto de ámbito estatal como autonómico ${ }^{69}$. En efecto, la mayoría de estos acuerdos contempla la actuación de las comisiones paritarias como requisito previo para acceder a los mecanismos de solución extrajudicial previstos en ellos. Así lo han establecido

\footnotetext{
${ }^{65}$ Granados (2002), pp. 118-119.

${ }^{66}$ Véanse, entre otras, las siguientes sentencias del Tribunal Supremo: Tribunal Supremo, STS 3311/1997, de 12 de mayo de 1997; Tribunal Supremo, STS 6398/1997, de 28 de octubre de 1997; Tribunal Supremo, STS 2071/1999, de 25 de marzo de 1999; Tribunal Supremo, STS 3820/1999, de 31 de mayo de 1999, y Tribunal Supremo, STS 7814/1999, de 7 de diciembre de 1999.

67 Ballester y Altés (1996), pp. 326 y ss., y Alfonso (2006), p. 16.

${ }^{68}$ Cavas (2007), p. 130.

${ }^{69}$ Martínez (1997), pp. 333-341, y Cavas (2007), pp. 133-134.
} 
los cinco Acuerdos para la Solución Autónoma de Conflictos Laborales (ASEC I - 1996, ASEC II - 2001, ASEC III - 2004, ASEC IV - 2009 y ASEC V - 2012) ${ }^{70}$.

Además, los artículos 63 LRJS, en relación con todos los litigios, y 156.1 LRJS, específicamente para los procesos de conflictos colectivos, admiten que la intervención de las comisiones paritarias pueda sustituir el trámite procesal de la conciliación previa obligatoria, siempre que así se establezca en los acuerdos interprofesionales o en los convenios marco que pueden suscribir las organizaciones sindicales y las asociaciones patronales más representativas, de carácter estatal o autonómico, al tenor del artículo 83.2 ET ${ }^{71}$.

\section{El valor jurídico de los pronunciamientos de las comisiones paritarias}

Luego de analizar el ámbito funcional de las comisiones paritarias en el ordenamiento jurídico español, es menester ahora estudiar la eficacia de los distintos acuerdos a que pueden arribar dichas comisiones en desempeño de sus competencias.

\subsection{El valor jurídico de los pronunciamientos de las comisiones paritarias en materia de interpretación general de los convenios colectivos}

Entre la interpretación aplicativa y la interpretación general que pueden efectuar las comisiones paritarias, es esta última la que ha generado los mayores debates en la doctrina y la jurisprudencia. En efecto, la defectuosa redacción del antiguo artículo 91 ET, único precepto legal que hacía mención explícita al papel de las comisiones paritarias en la interpretación general de los convenios colectivos, generó diversos problemas. Más allá de sus deficiencias gramaticales, la principal dificultad que planteaba dicho precepto era que no resolvía si la referencia a la competencia de la jurisdicción competente importaba asumir que la interpretación general del convenio -realizada por las comisiones paritarias- estaría siempre sometida a una posible revisión en el fondo por parte de la jurisdicción laboral.

La regulación que hoy ofrece el Estatuto de los Trabajadores es diametralmente distinta. Como ya hemos dicho, sin discutir la pertinencia o no de la regulación actual, claro está que es un avance normativo en relación con el reformado artículo 91. En efecto, la norma vigente esclarece la intención del legislador de dotar de cierta prioridad a la interpretacion realizada por la

\footnotetext{
70 Sobre la concreta articulación de los procedimientos autónomos de solución extrajudicial de conflictos previstos en los ASEC con las comisiones paritarias, véanse, como estudios señeros, VALDÉs (2003), pp. 37 y ss., y Cavas (2007), pp. 131 y ss.

71 Revísense algunos casos ejemplares en que ello ha ocurrido en Alfonso (2006), pp. 16 y ss.
} 
comisión paritaria de cada convenio colectivo, en desmedro de la intervención jurisdiccional a la que eventualmente se pueda ver enfrentada. Sin embargo, no es un tema pacífico, por cuanto la comprensión armónica y global de la normativa laboral española nos lleva a conclusiones confusas.

Tal es la entidad de esta cuestión y la disparidad de criterios que se han sostenido a su respecto, que se ha señalado que constituye uno de los puntos de máxima fricción entre la autonomía colectiva y la jurisdicción en el sistema español de negociación colectiva, desde su instalación temprana ${ }^{72}$. En efecto, detrás de la determinación del sujeto encargado de efectuar esta interpretación con carácter vinculante subyace la tensión entre el derecho a la tutela judicial efectiva y el derecho a la autonomía colectiva, ambos garantizados constitucionalmente.

Sobre esta cuestión, estrechamente vinculada al carácter facultativo o preceptivo de la intervención de las comisiones paritarias, se sostienen diversas posturas, una de las cuales afirma que la interpretación general que efectúan las comisiones paritarias es vinculante para la jurisdicción laboral, que no podrá rever el fondo de lo acordado por el citado órgano ante eventuales disconformidades que pueda plantear alguna de las partes en sede judicial. La conclusión anterior se apoya principalmente en la lectura del artículo 91.1 ET: "Sin perjuicio de las competencias legalmente atribuidas a la jurisdicción social, el conocimiento y resolución de las cuestiones derivadas de la aplicación e interpretación de los convenios colectivos corresponderá a la comisión paritaria de los mismos"; concretamente, entiende que la competencia de resolución de la jurisdicción laboral no impide que los convenios colectivos atribuyan funciones de esta naturaleza a las comisiones paritarias ${ }^{73}$.

En la misma línea argumental, un sector de la doctrina asevera que la interpretación auténtica realizada con carácter general por las comisiones paritarias tiene la eficacia que le otorguen los propios convenios colectivos. En efecto, son las partes negociadoras las que fijan no solo las competencias de la comisión, sino también el valor que quieren que se reconozca a sus resoluciones. Si estas le dan un valor meramente recomendatorio o informativo, siempre será posible el recurso ante la jurisdicción social. Lo mismo cabría predicar de aquellos casos en que el convenio no se refiera expresamente a esta cuestión, ya que dicha actitud envolvería la opción legítima de configurar la intervención de la comisión como órgano puramente asesor. En cambio, si convencionalmente se le concede a las actuaciones interpretativas de estos órganos eficacia resolutoria

72 Del Rey (1986), p. 119.

${ }^{73}$ Han sostenido esta tesis, entre otros: Del Rey (1986), p. 120; Morales (1998), pp. 268-269; Ojeda (2003), p. 795, y VALDÉS (2003), pp. 49-50. 
o vinculante, de arbitraje, o se establece que tienen el mismo valor que el convenio que interpretan, no resultará posible la intervención judicial salvo para impugnar la decisión de la comisión paritaria por ilegalidad o lesividad.

El principal sostén de la postura recién descrita radica en que es la propia autonomía colectiva de los negociadores, dotados de legitimación suficiente, la que opta de antemano por delegar en la comisión paritaria la interpretación del convenio colectivo, con carácter vinculante. Dicha posibilidad no encuentra reproche alguno en el ordenamiento jurídico español, que si bien reconoce y ampara el derecho a la tutela judicial, no obliga a las partes a acudir a la jurisdicción para resolver sus controversias jurídicas ${ }^{74}$.

Ahora bien, el artículo 91.4 ET agrega que "las resoluciones de la comisión paritaria sobre interpretación o aplicación del convenio tendrán la misma eficacia jurídica y tramitación que los convenios colectivos regulados en esta ley". Dicha disposición da luces de los requisitos que deben reunir dichas resoluciones para contar con su eficacia normativa general. En esa línea, dicha norma debe ser concordada con el artículo 91.2 ET y el 156 LRJS, según los cuales será necesario el cumplimiento de dos condiciones para que las resoluciones de la comisión paritaria cuenten con eficacia normativa general. En primer término, dicha eficacia general la tendrán las resoluciones emanadas de comisiones paritarias compuestas por las partes legitimadas para negociar convenios colectivos. En segundo lugar, dichas resoluciones deben recaer sobre un conflicto colectivo, realizando de esta forma una labor de interpretación o aplicación general ${ }^{75}$. En consecuencia, cumplidas dichas condiciones, la decisión de la comisión paritaria debe ajustarse a la misma tramitación que los convenios colectivos, cumpliendo con las etapas de depósito, registro y publicación oficial.

Puede añadirse una conclusión residual. Las resoluciones emanadas desde comisiones cuyas partes no tengan la legitimación necesaria para negociar el convenio, junto con las resoluciones que resuelvan litigios individuales al tenor del artículo 91.5 ET, no tienen la eficacia general del convenio ni tampoco son recurribles mediante la vía de impugnación de convenios colectivos.

Con todo, aún cuando la jurisprudencia admitiera el carácter vinculante de la interpretación que del convenio haga una comisión paritaria, siempre quedaría la posibilidad de controlar la legalidad de dicha interpretación, en el sentido de que no suponga una modificación de lo acordado en el convenio ${ }^{76}$.

\footnotetext{
${ }^{74}$ En este sentido: Alemán (2001), p. 51; Alfonso (2006), p. 14; Ballester y Altés (1996), pp. 304-305, 323 y ss., y SALA (2007), p. 981.

75 Montoya (2016), p. 128.

${ }^{76}$ Alfonso (2006), p. 17.
} 
Discusiones similares se plantean al analizar el valor jurídico de los acuerdos de las comisiones paritarias que ponen fin a conflictos laborales colectivos de interpretación sometidos a su conocimiento, aunque en estos supuestos debe considerarse además de las previsiones convencionales, el procedimiento extrajudicial utilizado ${ }^{77}$.

Más allá del valor que se reconozca a los pronunciamientos interpretativos de las comisiones paritarias respecto de las competencias de los tribunales de justicia, se debe tener presente que las discusiones alcanzan también a la extensión personal de dicha eficacia jurídica. En este sentido, por algunos se ha defendido que el carácter vinculante de las resoluciones de las comisiones paritarias solo alcanzaría a los firmantes del convenio, como corolario del carácter obligacional que podría revestir a las cláusulas que cobijan estas funciones ${ }^{78}$. Por el contrario, otro sector de la doctrina entiende que, al ser la comisión paritaria un órgano delegado de las partes negociadoras, la interpretación general que hagan del convenio vincula a todos aquellos que se encuentran dentro de su ámbito de aplicación ${ }^{79}$.

\subsection{El valor jurídico de los pronunciamientos de las comisiones paritarias en ejercicio de otras funciones}

Menos compleja resulta la determinación del valor jurídico de los pronunciamientos de las comisiones paritarias en ejercicio de funciones diversas a la interpretación general del convenio. En efecto, la mayor complicación en estos casos parece ser la dificultad de identificar todos y cada uno de los cometidos que pueden desempeñar estos órganos, a efectos de determinar la eficacia jurídica de sus distintos acuerdos, dada la amplitud y diversidad con que aparecen el panorama negocial.

Intentando dar cuenta de las principales categorías funcionales que se plantean respecto de las comisiones paritarias, cabe señalar que en general, cuando realizan estudios o labores de asesoramiento, sus informes constituyen meras propuestas, desprovistas de eficacia jurídica intrínseca, sin perjuicio de que puedan ser recogidos en futuros instrumentos normativos de carácter

\footnotetext{
77 RodríGuez (2006), pp. 268 y ss.

78 Ballester y Altés (1996), p. 324; Alfonso (2006), p. 16, y Ramírez (2007), p. 200. Sobre la discusión acerca de la naturaleza jurídica normativa u obligacional de la cláusula convencional que crea la comisión paritaria, véase CAVAS (2007), pp. 118-119.

79 Apilluelo (1997), p. 268, y Rodrícuez (2006), p. 443. En el mismo sentido, véase la sentencia de la Audiencia Nacional, SAN 4599/2017, de 11 de diciembre de 2017.
} 
colectivo. En sí mismos, por tanto, dichos informes no vinculan ni a las partes ni a los tribunales ${ }^{80}$.

Hay también funciones cuyo ejercicio no tiene como producto el pronunciamiento expreso de la comisión, como ocurre con la recepción de documentos e informes, el registro de determinadas actividades o circunstancias, la participación en diversas reuniones y asambleas, entre otras. Asimismo, existen cometidos que se cumplen realizando actuaciones ante terceras personas u órganos, como ocurre en general con la función de vigilancia del convenio, que puede concretarse en una notificación o en una denuncia ante los organismos administrativos o judiciales correspondientes, o ante las propias representaciones de las partes, con la eficacia propia de dichos actos ${ }^{81}$.

De otra parte, en aquellos casos en que la comisión se desempeña como órgano de aplicación del convenio, la eficacia de sus actuaciones es la propia de un acto de administración, que vincula a las partes regidas por el convenio siempre que aquellas se realicen en conformidad a los criterios previamente pactados. De todas formas, dichas actuaciones podrán ser objeto de fiscalización posterior en sede judicial. Vale hacer en este punto una salvedad respecto de las posibles actuaciones de las comisiones paritarias en materia de descuelgues. Dado que las decisiones de la comisión en estos casos se basan principalmente en criterios económicos y de oportunidad, resulta sensato pensar que el control jurisdiccional en estos casos se limite a cuestiones formales, sin alcanzar a dichos criterios extrajurídicos, salvo supuestos extremos.

Finalmente, cuando las comisiones paritarias realizan labores de integración del convenio o complemento del mismo, sus actuaciones se integran en el contenido del convenio y por tanto gozan de su misma eficacia, siempre que no traspasen la esfera reservada a la actividad de negociación y respeten las bases genéricas fijadas en el convenio ${ }^{82}$.

\section{Contrapunto: Las comisiones bipartitas reconocidas por la Ley $N^{\circ} \mathbf{2 0 . 9 4 0}$ en Chile}

En este apartado no se pretende agotar el desarrollo que estos temas han tenido en el sistema de relaciones laborales chileno, sino que se procura presentar ciertos elementos fácticos y normativos que permiten hacer un contrapunto

\footnotetext{
80 Morales (1998), pp. 338 y ss.

81 Se ha cuestionado la escasa eficacia práctica de las actuaciones de las comisiones paritarias en la vigilancia del cumplimiento del convenio en atención a que, por lo general, no se las dota de instrumentos ejecutivos. Véase al respecto MAteos (2004), pp. 279 y ss.

82 Véase, sobre estas cuestiones, el estudio de Alfonso (2006), pp. 77 y ss.
} 
respecto del modelo español, recién analizado. Concretamente, cabe ahora dar breve cuenta de la regulación legal de las comisiones bipartitas que pueden incluirse en los instrumentos colectivos ${ }^{83}$, conforme al régimen jurídico establecido por la Ley $\mathrm{N}^{0} 20.940^{84}$.

Tanto en el sistema español como en el chileno, las comisiones bipartitas surgieron de prácticas negociales espontáneas, sin reconocimiento legal explícito y sin una funcionalidad relevante. Sin embargo, en España han podido desarroIlarse al alero de reformas normativas y de un sistema de relaciones colectivas robusto, cuestión que no ha ocurrido en nuestro país, según comentaremos.

Antes de la Reforma Laboral que inició su vigencia en 2017, no era posible identificar disposiciones que ordenaran imperativamente -ni tampoco de forma promocional- el encuentro de las partes de la negociación colectiva en un espacio con las características y funciones de las comisiones paritarias españolas.

Sin embargo, en el Código del Trabajo de 1931 es posible encontrar un primer atisbo de comisiones bipartitas en las relaciones colectivas del trabajo. Las juntas permanentes de conciliación se configuraban como una comisión bipartita dispuesta y regulada en la ley, teniendo como principal función promover la conciliación obligatoria entre las partes de un conflicto colectivo, especialmente en caso de huelga, circunstancia en que la actuación de la junta permanente era obligatoria ${ }^{85}$. Dichos órganos eran integrados por seis representantes: tres de la parte empleadora, dos de los obreros y uno de los empleados ${ }^{86}$. La comisión era presidida por la administración laboral de la época, sin derecho a voto. Así las cosas, la junta permanente se constituía como un espacio de concurrencia obligatoria para las partes en caso de conflicto, especialmente previo a realizar la huelga.

Las diferencias entre dicho primer intento de institucionalización del diálogo bipartito y las comisiones paritarias del ordenamiento español son claras y rotundas. La primera de ellas es su configuración al margen del proceso de negociación colectiva, toda vez que las juntas permanentes no eran parte del

${ }^{83}$ En Chile, la denominación genérica de "instrumento colectivo" envuelve al contrato colectivo, convenio colectivo y fallo arbitral (se discute jurisprudencialmente si el acuerdo de grupo negociador tiene también la naturaleza de instrumento colectivo). En el sistema español, en cambio, el "convenio colectivo" es la fórmula genérica, y podrá clasificarse en estatutario y no estatutario, dependiendo de si cumple o no las reglas del ET.

${ }^{84}$ La Ley N ${ }^{\circ} 20.940$, que moderniza el sistema de relaciones laborales, fue publicada el 8 de septiembre de 2016 y entró en vigencia plena el 1 de abril de 2017.

${ }^{85}$ Artículo 510, Decreto con Fuerza de Ley No 178, de 1931 (Código del Trabajo de 1931).

${ }^{86}$ La distinción -hoy derogada- entre obreros y empleados obedecía al tipo de actividad del trabajador. 
contenido mínimo del contrato colectivo ${ }^{87}$. Además, su constitución era obligatoria en todos los departamentos (regiones) del país, siendo su regulación determinada heterónomamente en todos sus aspectos, no siendo posible que las partes del conflicto acordaran su funcionamiento previamente. La función de las juntas permanentes era la promoción de la conciliación entre las partes en conflicto, careciendo de las facultades antonomásticas de las comisiones paritarias, como son la interpretación y aplicación del contrato colectivo.

Sin perjuicio de las diferencias mencionadas, las juntas permanentes son el primer acercamiento a un modelo alternativo de solución de conflictos colectivos, en el cual las partes -de forma obligatoria- debían analizar y estudiar formas de solución que satisficieran sus intereses.

Enfocándonos ahora en las comisiones bipartitas con regulación vigente en Chile y España, surge como un elemento semejante entre ambos institutos, conforme adelantamos, su nacimiento como práctica negocial. La utilidad primigenia de la institución paritaria -en ambos casos- ha sido la de facilitar el entendimiento entre las partes que acuden a la negociación de un instrumento colectivo, en un espacio de convergencia debidamente regulado de forma autónoma, que dé garantía de cercanía y conocimiento acabado del conflicto, y que tenga la posibilidad -y habilidad- de proponer soluciones que estén estrechamente relacionadas con las partes, sus intereses y el conflicto.

España ha transitado un largo recorrido para consolidar los contornos orgánicos de las comisiones paritarias, para dilucidar la utilidad que les reportan a las partes negociadoras y para definir su ámbito funcional. Según hemos dicho, su régimen jurídico actual representa una mixtura de características periféricas heterónomas con fuertes elementos autónomos.

El panorama actual de la legislación chilena con relación a la institución paritaria es categóricamente diverso al caso español. Lejos de adoptar medidas como la inclusión del órgano paritario en el contenido mínimo exigible a todo instrumento colectivo, la norma vigente opta por referirse a la eventual preferencia que los agentes negociadores puedan tener por estas comisiones. En efecto, la única disposición normativa que el ordenamiento jurídico actual contempla con relación a las comisiones bipartitas es el artículo 321 del Código del Trabajo, reconocimiento legal exiguo y menos expresivo que la normativa española de referencia.

En lo pertinente, el referido artículo 321 dispone que los instrumentos colectivos podrán contener, adicionalmente a su contenido obligatorio, "la

${ }^{87}$ El contenido mínimo del contrato colectivo, bajo la vigencia del Código de 1931, era: a) sector industrial que se encontrará afecto al contrato; b) lugar en el que regirá; c) fecha de comienzo de su vigencia; d) plazo; e) normas de prórroga del contrato, y f) normas sobre su desahucio. 
constitución de una comisión bipartita para la implementación y seguimiento del cumplimiento del instrumento colectivo o mecanismos de resolución de las controversias" $" 88$.

Claramente el legislador nacional opta por una posición normativa lejana y referencial, privando a las comisiones bipartitas de una regulación legal que las fortalezca y fomente su aplicación. En efecto, la norma citada entrega a las partes negociadoras la posibilidad de incluir una comisión bipartitita en el instrumento colectivo y deja en sus manos su regulación, limitando empero su funcionalidad a la implementación y seguimiento del cumplimiento del instrumento colectivo (y eventualmente a la solución autónoma de conflictos, con las prevenciones que enseguida veremos).

Esta fórmula normativa se aparta del referente español, que otorga -directa o indirectamente- a las comisiones paritarias elementos de soporte más sólidos. Primero, al establecer el órgano paritario como contenido mínimo del convenio colectivo, y segundo, al reconocerles funciones de la mayor importancia (aplicación e interpretación del convenio y resolución de conflictos colectivos).

La regulación que la normativa vigente en Chile ofrece a las comisiones bipartitas está lejos de motivar su existencia, por lo que no es posible proyectar que los índices previos a la última reforma laboral vayan a mejorar. En efecto, según el Anuario Estadístico de la Dirección del Trabajo, solo un 1,1 \% de los instrumentos colectivos que iniciaron su vigencia en el año 2016 incluyó cláusulas sobre la vigilancia del cumplimiento del convenio o contrato, y apenas un 9,9 \% incluyó cláusulas que regularan alguna forma alternativa de solución de conflictos $^{89}$. Sin lugar a dudas, lo anterior responde al poco -o nulo- incentivo que la normativa laboral ofrece al órgano paritario y sus funciones.

En definitiva, las limitaciones funcionales de las comisiones bipartitas chilenas, establecidas en la ley, merman significativamente su proyección de desarrollo en los instrumentos colectivos. El artículo 321 del Código del Trabajo, inserto en un modelo de regulación heterónoma que restringe la autonomía colectiva, no da espacio suficiente para que sean las partes negociadoras las que determinen funciones relevantes para estas comisiones, que estimulen su constitución ${ }^{90}$.

En un ejercicio de analogía normativa, podemos establecer que la función de implementación del instrumento colectivo corresponde a la función aplicativa establecida en el artículo 91.1 ET. La comisión sería responsable, entonces, de

${ }^{88}$ Precepto incluido en la legislación vigente a través de la citada Ley № 20.940, de 2016.

89 Dirección del Trabajo (2016).

90 Para una visión panorámica del modelo chileno de relaciones laborales, véase RoJAS y TAPIA (2015), pp. 135-173. 
aquellas actividades necesarias para la gestión y materialización del contenido del respectivo instrumento colectivo. Por su parte, la función de seguimiento del instrumento colectivo corresponde, en el sistema español, a la vigilancia del cumplimiento de este, entendida como la facultad para interpelar a las partes negociadoras para que mantengan una postura activa ante los posibles incumplimientos del acuerdo colectivo y, consiguientemente, denuncien sus violaciones a la otra parte o ante los órganos competentes, administrativos o judiciales ${ }^{91}$.

Como consecuencia de la realidad normativa de las relaciones colectivas de trabajo en Chile, las funciones recién mencionadas, que podrían otorgarse a las comisiones bipartitas, son subsumidas generalmente por la actividad propia del sindicato negociador. En efecto, a consecuencia del modelo de negociación colectiva esencialmente rígido, lo corriente es que sea el sindicato negociador quien asuma las funciones de vigilar la correcta aplicación y cumplimiento de lo pactado y, a su vez, que la parte empleadora sea quien se ocupe de la aplicación y materialización de lo convenido, actividades que, por cierto, se realizan sin interacción permanente e institucionalizada entre las partes que negociaron el instrumento colectivo.

La tercera función que el ordenamiento jurídico laboral chileno reconoce al órgano bipartito está referida a la solución alternativa de conflictos colectivos, reflejo -solamente aparente- de lo dispuesto en el artículo 91.1 ET. La proyección de funcionalidad de dicho rol de las comisiones en Chile queda fuertemente limitada por la actividad de la administración laboral. En general, los mecanismos de solución alternativa de conflictos laborales son operados en Chile por la Dirección del Trabajo ${ }^{92}$. Su rol en la promoción y dirección de la autocomposición de conflictos está presente tanto en conflictos individuales como en conflictos colectivos de trabajo.

Los datos arriba referidos demuestran que la concurrencia de las partes a los distintos métodos alternativos de solución de conflictos se produce fuera del instrumento colectivo, ya que ellas recurren principalmente a procedimientos externos asistidos por la autoridad administrativa, y no mediante mecanismos contemplados por la autonomía colectiva.

Ahora bien, la convivencia funcional entre la administración laboral y las comisiones paritarias en el ámbito de la composición de conflictos deja en evidencia otra diferencia entre el modelo español y chileno de regulación funcional de las comisiones bipartitas: la interpretación del instrumento colectivo.

\footnotetext{
91 Alemán (2001), p. 81.

92 La excepción en Chile es el arbitraje, operado por un tribunal arbitral. De todos modos, la Dirección del Trabajo supervigila esta forma de solución alternativa de conflictos colectivos, con diversas menciones legales.
} 
Como ya hemos señalado, las facultades que el ordenamiento español otorga a las comisiones paritarias en materia de solución de conflictos son una consecuencia necesaria de una de las funciones que por antonomasia poseen: la actividad hermenéutica del convenio colectivo. En efecto, la solución extrajudicial de conflictos es una materia íntimamente ligada a la labor interpretativa de las comisiones bipartitas, toda vez que al establecer el sentido y alcance de las cláusulas del convenio pueden resolverse también las discrepancias surgidas en torno a ellas, evitando la judicialización del conflicto. Es por ello que la mediación, la conciliación y el arbitraje son entendidos como instrumentos funcionales al cumplimiento del objeto primordial de las comisiones paritarias -la interpretación del convenio- en supuestos de conflictos laborales principalmente de carácter colectivo ${ }^{93}$.

Así pues, la ausencia de la labor interpretativa del instrumento colectivo en el actual artículo 321 del Código del Trabajo chileno despoja a las comisiones bipartitas de la principal función otorgada en el ordenamiento español y, justamente, de la función que justifica gran parte de los distintos roles que les son asignados, ya sean por ley o por la autonomía colectiva.

Ante esta omisión, ¿podría la comisión bipartita interpretar lo pactado colectivamente? La facultad de interpretación de los instrumentos colectivos fue un tema de ardua contradicción entre las facultades arrogadas por la administración laboral, por un lado, y las facultades exclusivas y excluyentes del Poder Jurisdiccional, por otro.

A comienzos de la década de los 90, la Dirección del Trabajo sostenía que el ordenamiento jurídico le otorgaba la facultad para interpretar los instrumentos colectivos $^{94}$, argumentando que para fiscalizar su cumplimiento era imperativo fijar el sentido y alcance de sus cláusulas.

La jurisprudencia de la Corte Suprema, en cambio, rechaza esa postura arguyendo que si bien la Dirección del Trabajo se encuentra facultada para fiscalizar el cumplimiento de la legislación laboral y para interpretarla, "se ha arrogado facultades propias y excluyentes de los tribunales competentes en esta materia, esto es, los Juzgados del Trabajo, quienes de conformidad a lo previsto en el artículo 420 letra a) del Código Laboral, son los competentes para conocer de las cuestiones suscitadas entre empleadores y trabajadores por aplicación de las normas laborales o derivadas de la interpretación y aplicación de los contratos individuales o colectivos del trabajo o de las convenciones y fallos arbitrales en materia laboral" ${ }^{\prime \prime 5}$.

93 Ballester y Altés (1996), p. 311, y Sala y Albiol (2002), p. 336.

94 Por todos, Dictamen № 8.230/283, de 16 de diciembre de 1991.

${ }_{95}$ Corte Suprema, rol № 2796-2012, de 27 de agosto de 2012; en el mismo sentido, Corte Suprema, rol No 994-2011, de 25 de mayo de 2011. 
En este escenario, poco y nada puede hacer la comisión bipartita en materia de interpretación de instrumentos colectivos, siendo esta otra manifestación de la limitación a la autonomía colectiva que caracteriza al modelo chileno de relaciones laborales. Así las cosas, la regulación del artículo 321 del Código del Trabajo se aparta de la construcción dogmática española respecto de la noción de administración del convenio colectivo, toda vez que le priva de su función hermenéutica, asunto que socaba y limita todas las actividades que bajo la administración del contrato colectivo pudiesen realizar.

\section{Conclusiones}

Las comisiones paritarias se han venido presentando en el sistema español de relaciones laborales como los órganos tradicionales de administración y gestión de los convenios colectivos. De esta forma, la problemática sobre estos institutos se ha centrado no tanto en la determinación teórica de su ámbito competencial, sino más bien en la definición de las actividades que pueden englobarse en él.

Para ello, son diversos los elementos que desempeñan un rol definitorio en las actuaciones que puede realizar -o no- el órgano paritario. El primero de ellos es el marco legal, que sirve de basamento para la configuración jurídica de estas comisiones. La actual regulación otorga una amplísima libertad a la autonomía colectiva para delegar en las comisiones paritarias cuantas cuestiones se estimen pertinentes. Los convenios colectivos, por su parte, han respondido positivamente al incentivo presentado por el legislador, dotando de una amplia y diversa constelación de funciones y facultades a estos órganos.

En este laxo panorama competencial, ha sido la jurisprudencia -constitucional primero y ordinaria después- el principal ente limitador para un desarrollo más eficaz y activo de estas comisiones, tanto por la aún constreñida concepción judicial de la noción de administración del convenio, como también por los limitados efectos jurídicos que reconoce a los acuerdos de aquellas.

Pese a todo, las comisiones paritarias son actualmente un vehículo de aproximación hacia un modelo más dinámico de negociación colectiva, un instrumento de adaptación de lo pactado a la cambiante realidad normada y un importante escenario para fórmulas autónomas de solución de conflictos laborales.

Sin desconocer la distinción entre los actos de administración y los actos de negociación, con las consiguientes exigencias de legitimación para los sujetos que los realizan, no puede negarse que las competencias administradoras de las comisiones paritarias no se agotan en la mera gestión del convenio, sino que pueden alcanzar a la regulación de determinadas condiciones de trabajo, cuando así conste en el propio convenio, y de conformidad a la ley. En efecto, depende en gran parte de la autonomía colectiva servirse de las ventajas funcionales que ofrece la comisión paritaria. 
En cuanto al valor jurídico de los pronunciamientos y acuerdos de las comisiones paritarias, las mayores problemáticas se plantean respecto a la eficacia de sus actuaciones interpretativas con carácter general. En este sentido, es loable el esfuerzo de un sector de la doctrina por mantener vigente el debate sobre los límites del control que pueden efectuar los órganos jurisdiccionales en esta materia. Si lo que se pretende es dar un paso adelante en la dinamización de la negociación colectiva en el actual modelo normativo español, necesariamente debe superarse la rigidez que ha primado en las soluciones judiciales que se han venido refiriendo a esta cuestión, de modo de reconocer márgenes reales de eficacia jurídica a las intervenciones que conforman su núcleo funcional más básico.

Por ello, concordamos con la tesis que estima que dichos acuerdos gozan de eficacia jurídica erga omnes respecto todos aquellos incluidos en el ámbito de aplicación del convenio y son vinculantes para los tribunales, siempre que ese haya sido el valor reconocido por la autonomía colectiva. De esta forma, el control judicial debe limitarse a un mero examen de constitucionalidad y legalidad que respete el pronunciamiento interpretativo de la comisión, asumiéndolo siempre que sea una de las interpretaciones posibles del convenio ${ }^{96}$. Lo anterior en nada merma el respeto al derecho a la tutela judicial, toda vez que es el mismo sistema jurídico el que prevé y permite dicha posibilidad de actuación, y en todo caso, reserva a los órganos jurisdiccionales la competencia para revisar la legalidad o lesividad de estos actos.

Sumado a lo anterior, la importancia y utilidad reportada por las comisiones paritarias en la resolución de conflictos laborales deben ser subrayadas, por cuanto ofrecen un espacio de encuentro compuesto por las mismas partes en conflicto y las encaminan hacia el logro de acuerdos satisfactorios para sus propios intereses.

El panorama de las recién estrenadas comisiones bipartitas es radicalmente distinto en el caso chileno. Teniendo en cuenta las diferencias estructurales entre los modelos de relaciones laborales de ambos países $^{97}$, la excesiva rigidez del sistema chileno no otorga el espacio necesario para el desenvolvimiento de las cualidades de un órgano como el estudiado.

La Ley $N^{\circ} 20.940$ estableció la posibilidad de que las partes negociadoras acuerden la creación de una comisión encargada de la implementación y

\footnotetext{
${ }^{96}$ Alfonso (2006), pp. 80-81.

${ }_{97}$ Especialmente determinantes en la funcionalidad de las comisiones bipartitas son las diferencias en el ámbito de la negociación colectiva (articulada en diversos niveles, en España; de nivel de empresa, en Chile) y en la eficacia jurídica y personal de los instrumentos colectivos (eficacia normativa y erga omnes, en España; eficacia real y personal limitada, en Chile).
} 
seguimiento de lo pactado, así como también de la solución de conflictos colectivos. Sin embargo, en una perspectiva proyectiva, se avizora una limitada viabilidad práctica a su funcionamiento, toda vez que la instancia bipartita no está facultada para interpretar lo negociado por las partes del instrumento colectivo. Como vimos, dicha facultad corresponde exclusivamente a los tribunales de justicia. Esta limitada funcionalidad está siendo determinante en el escaso interés de los actores de las relaciones laborales por constituir y regular estas comisiones.

En ese contexto, son legítimos los cuestionamientos a la virtualidad práctica que la comisión bipartita puede brindar en el actual modelo normativo chileno, puesto que, sin la posibilidad de realizar una actividad hermenéutica de lo acordado por las partes de la negociación, difícilmente se pueden proyectar actuaciones útiles de aplicación y vigilancia del instrumento colectivo y, sobre todo, de resolución de conflictos colectivos. Dichas actividades, como certeramente lo advierte la doctrina española, exigen necesariamente el ejercicio de funciones interpretativas de la comisión paritaria ${ }^{98}$.

Ahora bien, el estudio del modelo español importa una contribución al actual debate sobre la solución de conflictos colectivos en Chile, principalmente en relación con la necesidad de reducir la cantidad de controversias resueltas en los órganos jurisdiccionales, a favor de métodos alternativos, determinados por las partes.

\section{BibLIOGRAFÍA CITADA}

Alemán PÁez, Francisco (1996): Las comisiones paritarias (España, Editorial Civitas).

(2001): "Las comisiones paritarias: Marco institucional y posibilidades operativas ante la renovación del ASEC de 1996", en: Temas Laborales: Revista Andaluza de Trabajo y Bienestar Social (№ 58), pp. 45-62.

Alemán PÁez, Francisco, y Rodríguez Crespo, María José (2005): “Aspectos orgánicos y funcionales de las comisiones paritarias. Panorama actual y líneas posibles de reforma", en: Relaciones Laborales (vol. I), pp. 257-298.

\footnotetext{
${ }_{98}$ Buena parte de las modificaciones introducidas por la Ley $\mathrm{N}^{\circ} 20.940$ están en la periferia del modelo de relaciones colectivas y su virtualidad depende en buena medida de elementos normativos que no han sido alterados. Es el caso de la nueva regulación de las comisiones bipartitas. Así las cosas, los avances no pasan de ser nominales en la perspectiva de valoración sistémica que exige la libertad sindical. En este sentido: Palomo (2016), p. 491.
} 
Alfonso Mellado, Carlos (1993): "Las funciones de la comisión paritaria en la interpretación del convenio colectivo", en: Revista Tribuna Social ( $\left.\mathrm{N}^{\circ} 28\right)$, pp. 14-19.

(2006): "La eficacia de los acuerdos de las comisiones paritarias de los convenios colectivos", en: Revista de Derecho Social (No 34), pp. 71-86.

Apilluelo Martín, Margarita (1997): La intervención de la comisión paritaria del convenio colectivo supraempresarial en la solución del conflicto de trabajo (España, CEDECS).

ARRIETA IDIAKEZ, Francisco (2014): "Autonomía colectiva y solución autónoma y/o extrajudicial de sus conflictos", en: ABEL LluCH, Xavier, Las medidas preventivas de conflictos jurídicos en contextos económicos inestables (España, Editorial Bosch), pp. 215-232.

Ballester Pastor, María, y Altés Tárrega, Juan Antonio (1996): "Las comisiones paritarias en la negociación colectiva", en: Revista Relaciones Laborales (No 2), pp. 304-339.

Cavas Martínez, Faustino (2007): “Las comisiones paritarias y la solución de los conflictos laborales derivados de la interpretación y aplicación del convenio colectivo", en: Revista del Ministerio de Trabajo y Asuntos Sociales ( $\left.\mathrm{N}^{\circ} 68\right)$, pp. 115-136.

Cruz Villalón, Jesús (1985): "La intervención de las comisiones paritarias de convenios colectivos en la resolución de conflictos", en: Revista de Política Social (No 146), pp. 205-238.

(2011): "El nuevo papel de la mediación y el arbitraje en los procesos de negociación colectiva", en: Revista Relaciones Laborales (№ 23), pp. 365-399.

Del Rey Guanter, Salvador (1986): "Arbitraje, comisiones paritarias y proceso", en: Temas Laborales: Revista Andaluza de Trabajo y Bienestar Social ( $\mathrm{N}^{\circ}$ 6), pp. 112-126.

Dirección del Trabajo (2016): "Anuario Estadístico". Disponible en: https:// www.dt.gob.cl/portal/1629/w3-propertyvalue-76577.html [visitado el 16.10.2018].

Escudero RodríGuez, Ricardo (Coord.) (2004): La negociación colectiva en España: Una visión cualitativa (España, Editorial Tirant lo Blanch).

(Coord.) (2002): Observatorio de la negociación colectiva (España, Comisiones Obreras). 
FERIA BASILIO, Iluminada (2012): Las comisiones paritarias y las facultades negociadoras convencionales tras el trienio transformador (España, XXX Jornadas Universitarias Andaluzas de Derecho del Trabajo y Relaciones Laborales).

FUNDACIÓN SIMA (2012): "Quinto acuerdo sobre solución autónoma de conflictos laborales (sistema extrajudicial)". Disponible en: http://fsima.es/wp-content/ uploads/asac-v.pdf [visitado el 22/11/2018].

García QuiNóńnez, Juan (2016): “Las comisiones paritarias en el ordenamiento jurídico español: Virtualidad y potencialidad dentro del contexto de la negociación colectiva", en: Revista Internacional y Comparada de Relaciones Laborales y Derecho del Empleo ( $\left.\mathrm{N}^{\circ} 2\right)$, pp. 51-82.

Garrigues Giménez, Amparo (1998): “Aspectos funcionales de las comisiones paritarias en los convenios colectivos: función negociadora y composición del órgano paritario (a propósito de la S.T.S. -Social- de 29 de abril de 1997)", en: Tribuna Social (No 89), pp. 116-122.

GIL SuÁREZ, Luis (1992): "Aplicación, administración e interpretación de los convenios colectivos", en: Cuadernos de Derecho Judicial. La negociación colectiva (Vol. III), pp. 187-248.

Goerlich Peset, José María (1988): "Notas sobre el régimen orgánico de la comisión paritaria del convenio (I)", en: Revista Actualidad Laboral, pp. 2109-2116.

GonzÁlez Ortega, Santiago (2013): "La comisión paritaria del convenio colectivo", en: Temas Laborales: Revista Andaluza de Trabajo y Bienestar Social (No 120), pp. 281-313.

Granados Romera, María Isabel (2002): "Balance y perspectivas del Sercla: Las comisiones paritarias y su defectuosa articulación en el sistema", en: Temas Laborales: Revista Andaluza de Trabajo y Bienestar Social ( $\mathrm{N}^{\circ}$ 65), pp. 109-128.

Hierro Hierro, Francisco (2016): “Ejemplos de cláusulas convencionales españolas para la solución extrajudicial de conflictos: las funciones de las comisiones mixtas", en: Revista Universidad de Extremadura (№ 33), pp. 26-42.

Kahn-Freund, Otto (1987): Trabajo y derecho (España, Centro de Publicaciones del Ministerio de Trabajo y Seguridad Social).

Martínez Girón, Jesús (1997): "La articulación de las comisiones paritarias y los servicios no estatales de mediación y arbitraje", en: Revista Española de Derecho del Trabajo (№ 83), pp. 333-342.

Mateos Beato, Alfredo (2004): La aplicación e interpretación de la negociación colectiva: El papel de las comisiones mixtas y otros órganos de composición 
de las partes (España, Centro de Publicaciones del Ministerio de Trabajo y Asuntos Sociales).

Montoya Melgar, Alfredo (2016): "Las comisiones paritarias", en: Revista del Ministerio del Empleo y Seguridad Social (No 123), pp. 97-108.

Morales Ortega, José Manuel (1998): La administración del convenio colectivo (España, Editorial Civitas).

Ojeda Avilés, Antonio (2003): Derecho sindical (España, Editorial Tecnos).

Palomeque López, Manuel Carlos (1990): “Administración del convenio colectivo y solución de conflictos laborales" (España, Centro de Publicaciones del Ministerio de Trabajo y Asuntos Sociales).

PALOMO, Rodrigo (2016): “Expectativa vs. realidad en la reforma laboral chilena. El nuevo derecho de información de los sindicatos como paradigma de una reforma transaccional", en: Derecho Laboral ( $\left.N^{\circ} 263\right)$, pp. 475-492.

Ramírez Martínez, Juan (Dir.) (2007): Curso de derecho del trabajo (España, Editorial Tirant lo Blanch).

Rodríguez CRESPO, María José (2006): La administración del convenio colectivo (España, Consejo Económico y Social de Andalucía).

RoJAs, Irene, y TAPIA, Francisco (2015): "Las relaciones laborales colectiva en Chile", en: Mangarelli, Cristina; Sala, Tomás, y Tapia, Francisco (Coord.), Las relaciones laborales colectivas en América Latina y España (España, Tirant lo Blanch), pp. 135-173.

Roldán Martínez, Aránzazu (2014): "Algunos efectos de un nuevo modelo de negociación colectiva más dinámico y cercano a la empresa: conexiones, relaciones e interferencias entre convenios y acuerdos colectivos", en: Revista de Derecho Social (No 67), pp. 211-238.

Sala Franco, Tomás, y Albiol Montesinos, Ignacio (2002): Derecho sindical (España, Editorial Tirant lo Blanch).

Sala Franco, Tomás (Dir.) (2007): Relaciones laborales 2007 (España, Editorial Tirant lo Blanch).

Serrano Olivares, Raquel (2003): Los compromisos de empleo en la negociación colectiva (España, Editorial Tirant lo Blanch).

TARABINI-CAStellani AzNAR, Margarita (1999): "Las competencias de administración y negociación de las comisiones paritarias en especial tras la reforma de 1994", en: Relaciones Laborales (tomo II), pp. 387-406.

VALDÉs DAL-Ré, Fernando (2003): "Las comisiones paritarias y las soluciones de conflictos en el marco del ASEC. Algunos puntos críticos (I)", en: Relaciones Laborales (Vol. I), pp. 37-48. 


\section{JURISPRUDENCIA CITADA}

España, Tribunal Constitucional:

STC 12/1983, de 22 de febrero de 1983

STC 73/1984, de 27 de junio de 1984

STC 9/1986, de 21 de enero de 1986

STC 39/1986, de 31 de marzo de 1986

STC 187/1987, de 24 de noviembre de 1987

STC 184/1991, de 30 de septiembre de 1991

STC 213/1991, de 11 de noviembre de 1991

STC 217/1991, de 14 de noviembre de 1991

STC 222/2005, de 12 de septiembre de 2005

España, Tribunal Supremo:

STS 2832/1991, de 30 de mayo de 1991 (AR 5233)

STS 6665/1991, de 27 de noviembre de 1991 (AR 8420)

STS 938/1992, de 10 de febrero de 1992 (AR 1140)

STS 2589/1992, de 25 de marzo de 1992 (AR 1874)

STS 5068/1992, de 24 de junio de 1992 (AR 4669)

STS 12856/1993, de 28 de enero de 1993 (AR 375)

STS 3363/1993, de 25 de mayo de 1993 (AR 5533)

STS 1725/1994, de 14 de marzo de 1994 (AR 370)

STS 7211/1994, de 8 de noviembre de 1994 (AR 8600)

STS 7219/1994, de 8 de noviembre de 1994 (AR 8600)

STS 8360/1994, de 15 de diciembre 1994 (AR 8635)

STS 733/1995, de 14 de febrero de 1995 (AR 1524)

STS 3605/1995, de 20 de junio de 1995 (AR 5214)

STS 1909/1996, de 27 de marzo de 1996 (AR 2497)

STS 3409/1996, de 4 de junio de 1996 (AR 4883)

STS 5223/1996, de 2 de octubre de 1996 (AR 7682)

STS 7379/1996, de 19 de diciembre de 1996 (AR 9736)

STS 3311/1997, de 12 de mayo de 1997 (AR 4087)

STS 6398/1997, de 28 de octubre de 1997 (AR 7682)

STS 2071/1999, de 25 de marzo de 1999 (AR 3518)

STS 3820/1999, de 31 de mayo de 1999 (AR 6733) 
STS 4629/1999, de 29 de junio de 1999 (AR 5231)

STS 4934/1999, de 9 de julio de 1999 (AR 6161)

STS 7814/1999, de 7 de diciembre de 1999 (AR 9689)

STS 524/2000, de 28 de enero de 2000 (AR 1320)

STS 4310/2001, de 24 de mayo de 2000 (AR 5443)

STS 5729/2000, de 11 de julio de 2000 (AR 7208)

STS 9142/2000, de 12 de diciembre de 2000 (AR 2001/809)

STS 2882/2001, de 5 abril de 2001 (AR 4886)

STS 3775/2011, de 9 de mayo del año 2001 (AR 5201)

STS 8443/2011, de 30 de octubre de 2001 (AR 2002/2381)

STS 1805/2002, de 13 de marzo de 2002 (AR 5143)

STS 3475/2004, de 20 de mayo de 2004 (AR 5161)

STS 1672/2005, de 16 de marzo de 2005 (AR 3510)

STS 7665/2005, de 31 de octubre de 2005 (AR 2006/1305)

STS 2958/2006, de 8 de marzo de 2006 (AR 4663).

STS 7429/2006, de 8 de noviembre de 2006 (AR 8266)

STS 5715/2007, de 22 de junio de 2007

STS 1072/2010, de 18 de febrero de 2010

STS 4004/2010, de 25 de junio de 2010 (REC 78/2009)

STS 2237/2009, de 26 de marzo de 2013

STS 5304/2013, de 21 de octubre de 2013

STS 3066/2014, de 1 de abril de 2014

STS 407/2015, de 3 de febrero de 2015 (REC 74/2014)

STS 4234/2015, de 14 de septiembre de 2015 (AR 204/2014)

STS 5578/2015, de 11 de noviembre de 2015

STS 2131/2017, de 11 de marzo de 2017

STS 1463/2018, del 4 de abril de 2018 (AR 369/2018)

España, Audiencia Nacional:

SAN 4207/2017, de 26 de octubre de 2017 (REC 239/2017)

SAN 4599/2017, de 11 de diciembre de 2017 (REC 283/2017)

SAN 5174/2017, de 27 de diciembre de 2017 (REC 305/2017)

SAN 664/2018, de 2 de marzo de 2018 (REC 365/2017)

España, Tribunal Central de Trabajo:

Sentencia de 14 de enero de 1981 (AR 580) 
Sentencia de 14 de mayo de 1982 (AR 3250)

Sentencia de 8 de marzo de 1988 (AR 1983)

Sentencia de 7 de febrero de 1989 (AR 74)

Sentencia de 16 de enero de 1989 (AR 348).

Sentencia de 8 de marzo de 1989 (AR 114)

Sentencia de 23 de marzo de 1984 (AR 3039 y 3074)

Sentencia de 29 de marzo de 1989 (AR 151)

Sentencia de 5 de abril de 1989 (AR 171)

Sentencia de 9 de mayo de 1989 (AR 211)

Chile, Corte Suprema:

Red de Televisión Chilevisión con Escobar y otros (2011): Corte Suprema 25 mayo 2011 (recurso de queja) rol No 994-2011 en: www.pjud.cl.

Tricard S.A. con Inspección Provincial del Trabajo Petorca (2012): Corte Suprema 27 agosto 2012 (apelación protección) rol № 2796-2012 en: www.pjud.cl. 
